\title{
Trinucleotide repeats: a structural perspective
}

\section{Bruno Almeida, Sara Fernandes ${ }^{\dagger}$, Isabel A. Abreu $^{\dagger}$ and Sandra Macedo-Ribeiro*}

Instituto de Biologia Molecular e Celular, Universidade do Porto, Porto, Portugal

Edited by:

Thomas M. Durcan, McGill University,

Canada

Reviewed by:

Denis Soulet, Laval University, Canada Thomas M. Durcan, McGill University, Canada

*Correspondence:

Sandra Macedo-Ribeiro, Instituto de Biologia Molecular e Celular,

Universidade do Porto, Rua do Campo Alegre 823, 4150-180 Porto, Portugal

e-mail: sribeiro@ibmc.up.pt

\section{${ }^{t}$ Present address:}

Sara Fernandes, Shannon ABC,

Limerick Institute of Technology,

Limerick, Ireland;

Isabel A. Abreu, GplantS, Instituto de

Tecnologia Química e Biológica,

Oeiras, Portugal.
Trinucleotide repeat (TNR) expansions are present in a wide range of genes involved in several neurological disorders, being directly involved in the molecular mechanisms underlying pathogenesis through modulation of gene expression and/or the function of the RNA or protein it encodes. Structural and functional information on the role of TNR sequences in RNA and protein is crucial to understand the effect of TNR expansions in neurodegeneration. Therefore, this review intends to provide to the reader a structural and functional view of TNR and encoded homopeptide expansions, with a particular emphasis on polyO expansions and its role at inducing the self-assembly, aggregation and functional alterations of the carrier protein, which culminates in neuronal toxicity and cell death. Detail will be given to the Machado-Joseph Disease-causative and polyQ-containing protein, ataxin-3, providing clues for the impact of poly $\mathrm{Q}$ expansion and its flanking regions in the modulation of ataxin-3 molecular interactions, function, and aggregation.

Keywords: amino acid-repeats, microsatellites, protein complexes, protein aggregation, amyloid, protein structure

\section{TRINUCLEOTIDE REPEATS AND HUMAN DISEASE}

Trinucleotide repeat (TNR) expansions and their association with neurological disorders have been known for the past 20 years (La Spada et al., 1991). Expansion of CAG, GCG, CTG, CGG, and GAA repeats located in coding or non-coding sequences of different genes (summarized in Table 1; Figures $\mathbf{1}$ and 2 ) are associated with a diverse range of human monogenic diseases such as Spinobulbar Muscular Atrophy (SBMA, a.k.a. Kennedy disease), Huntington Disease (HD), Spinocerebellar Ataxias (SCAs), Oculopharyngeal Muscular Dystrophy (OPMD), Myotonic Type 1 (DM1), Fragile X-Associated Tremor Ataxia Syndrome (FXTAS), and Friedreich Ataxia (FRDA) (for a review see Orr and Zoghbi, 2007), with longer repeats being correlated with earlier age at onset and increased disease severity. These TNR are highly unstable and the repeat tract length can change between affected individuals within the same family and can be different in different tissues (La Spada, 1997; Brouwer et al., 2009). More interestingly, in the brain of patients affected by CAG expansions, differences in repeat instability have been found between specific cell types (Pearson et al., 2005; Gonitel et al., 2008; Lopez Castel et al., 2010). GCG repeats are usually shorter and reveal a higher stability in different tissues and across generations than CAG repeats. The dynamic nature of these DNA repeat expansions is a consequence of their capability to form different secondary structures, which interfere with the cellular mechanisms of replication, repair, recombination and transcription (for a recent review see Lopez Castel et al., 2010). The molecular mechanisms underlying pathogenesis in those disorders, either associated with mental retardation, neuronal, or muscular degeneration, might result from alterations in the levels of gene expression and/or the function of the RNA or protein it encodes, mechanisms that likely act in concert to influence the pattern of selective cell toxicity. Some of those toxicity mechanisms will be briefly discussed below.

\section{TRINUCLEOTIDE REPEATS AND RNA STRUCTURE}

The formation of hairpin structures within the TNR RNA is related to the gain in RNA toxic function, the major pathogenic mechanism associated with CUG and CGG repeat expansions in noncoding regions of DM1 and FXTAS transcripts, which was also shown to contribute to pathogenesis in CAG repeat disorders such as HD and Machado-Joseph disease (MJD, a.k.a. SCA3) (reviewed in Krzyzosiak et al., 2012). These duplex structures, whose stability is positively correlated with the repeat size (Napierala and Krzyzosiak, 1997), sequester dsRNA binding proteins involved in mRNA splicing such as CUG-binding protein (CUGBP) and muscleblind protein 1 (MBNL1) (Miller et al., 2000), inducing aberrant splicing in affected cells, compromising multiple intracellular pathways, affecting cell-quality control regulation, and ultimately resulting in cell dysfunction (Li and Bonini, 2010). Structural studies on model trinucleotide CUG, CAG, and CGG repeats forming double-stranded chains revealed the features induced by periodic $\mathrm{U}-\mathrm{U}, \mathrm{A}-\mathrm{A}$, and $\mathrm{G}-\mathrm{G}$ mismatches, and provided hints into the structural details of pathogenic RNAs that are recognized by RNAbinding proteins (Mooers et al., 2005; Kiliszek et al., 2010, 2011; Kumar et al., 2011; Parkesh et al., 2011). MBNL1 is composed of four zinc-containing RNA-binding domains arranged in two tandem segments, with the C-terminal zinc-finger pair displaying a GC-sequence recognition motif (Teplova and Patel, 2008) and interacting with the stem region of expanded CUG RNAs (Yuan et al., 2007). Electron microscopy analysis of MBNL1:CUG ${ }^{136}$ complexes showed that the pathogenic dsRNA forms a scaffold 


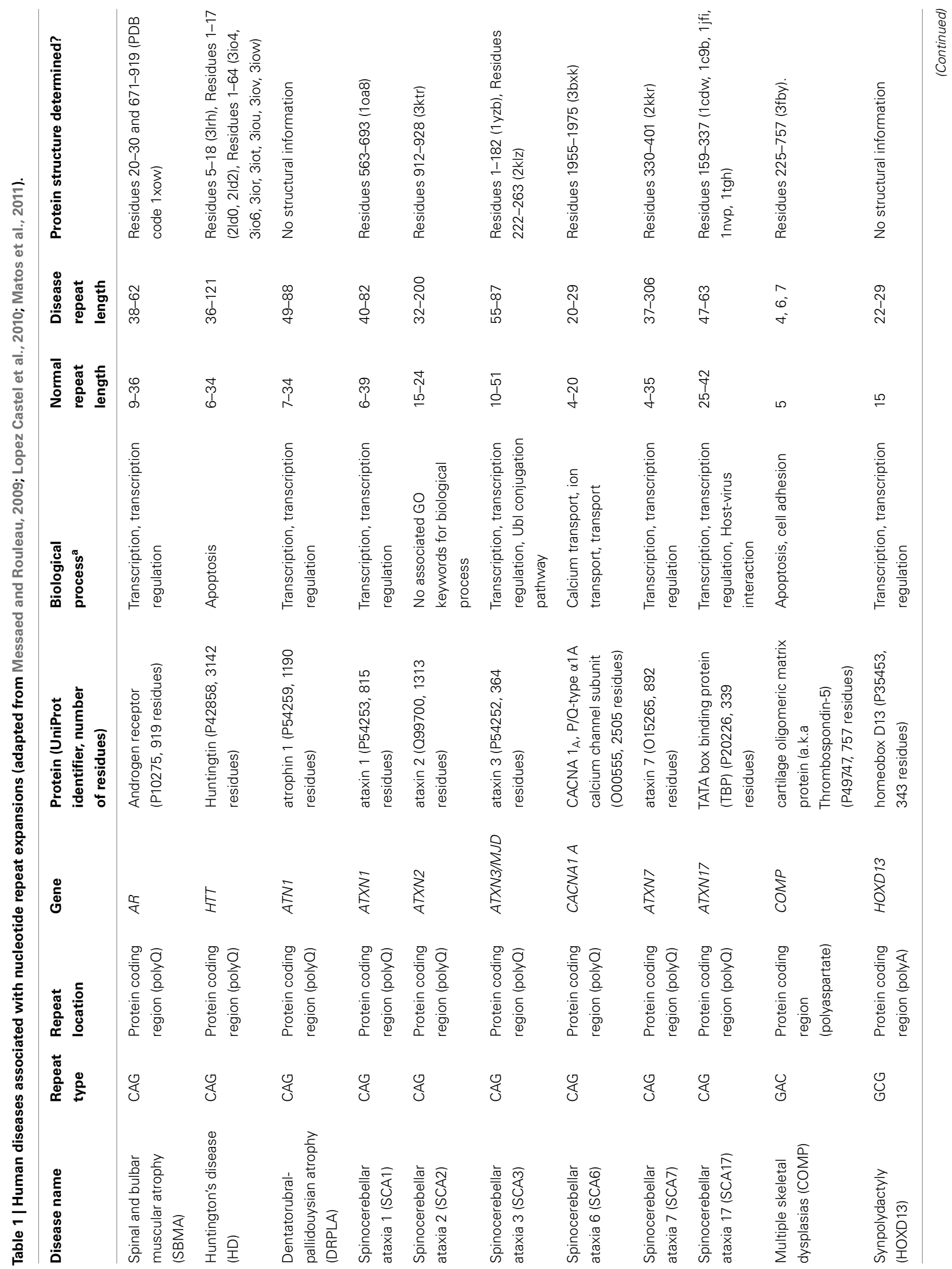




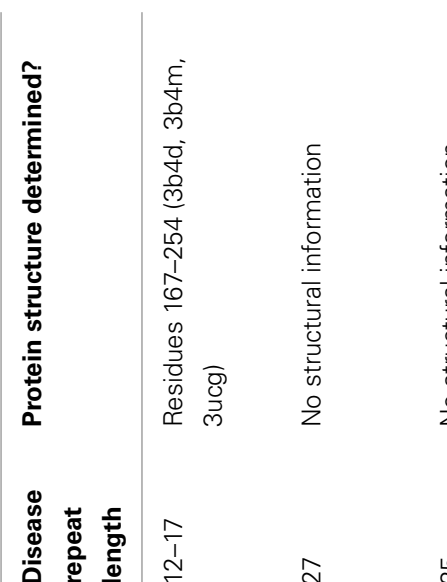

Iํ.

๙

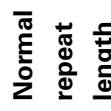

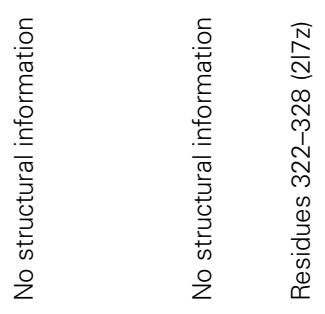

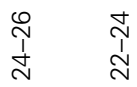

$\stackrel{\infty}{\square} \quad \stackrel{0}{!}$

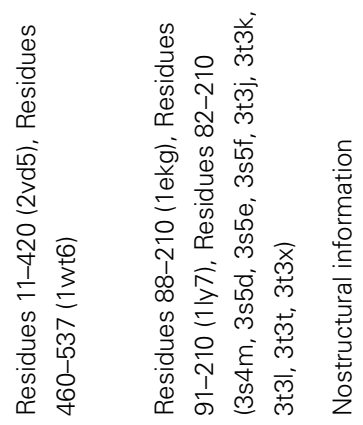

\begin{tabular}{llll}
0 & 8 & & \\
& 0 & 0 & 0 \\
1 & 0 & 1 & \multicolumn{1}{c}{}
\end{tabular}

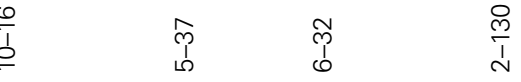
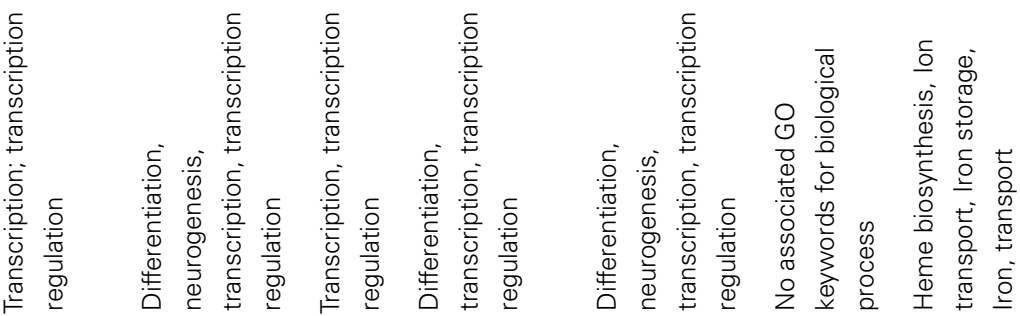

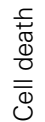
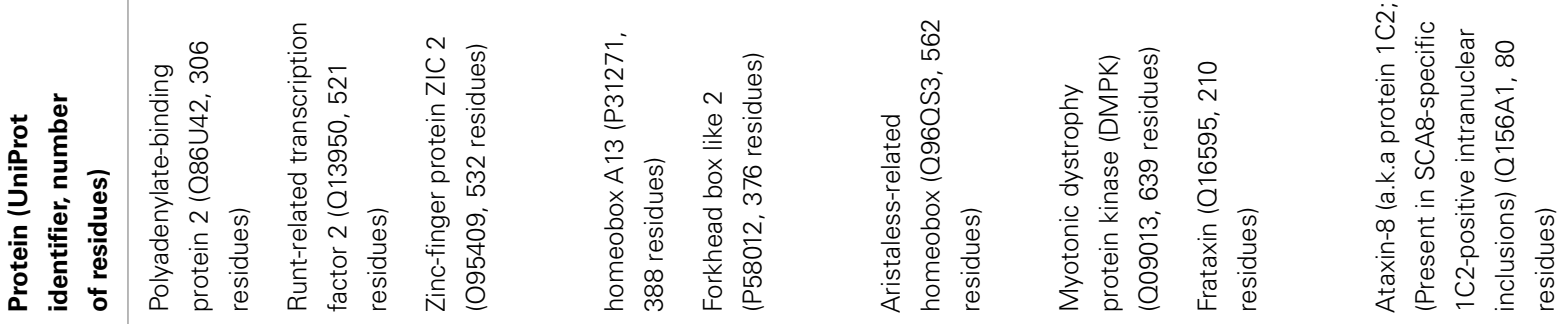

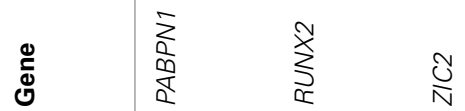

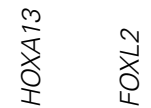

穻

$\sum_{0}^{\frac{k}{2}}$

妾

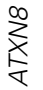

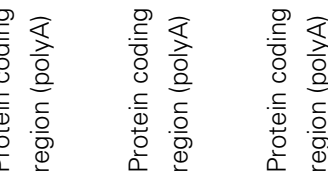

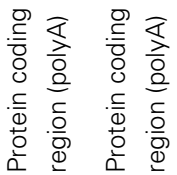

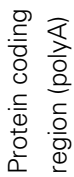

$\stackrel{\substack{5 \\ 5}}{m}$

을

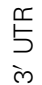

\begin{tabular}{l|lll} 
& & & \\
$\stackrel{0}{0}$ & 0 & 0 & 0 \\
\hdashline & 0 & 0 & 0
\end{tabular}

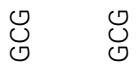

ভ্

안 종

ํํำ
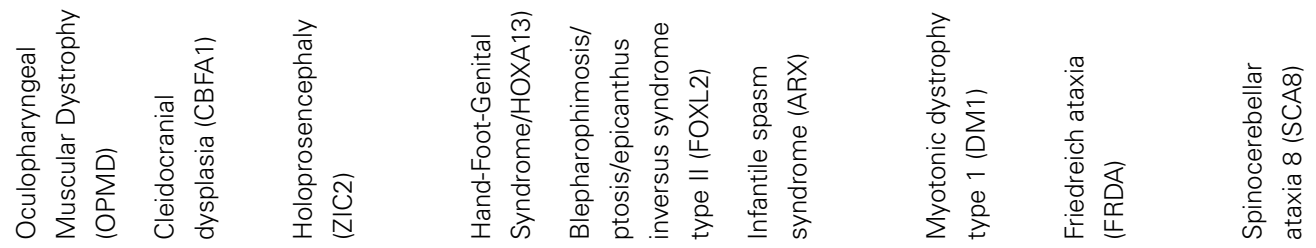


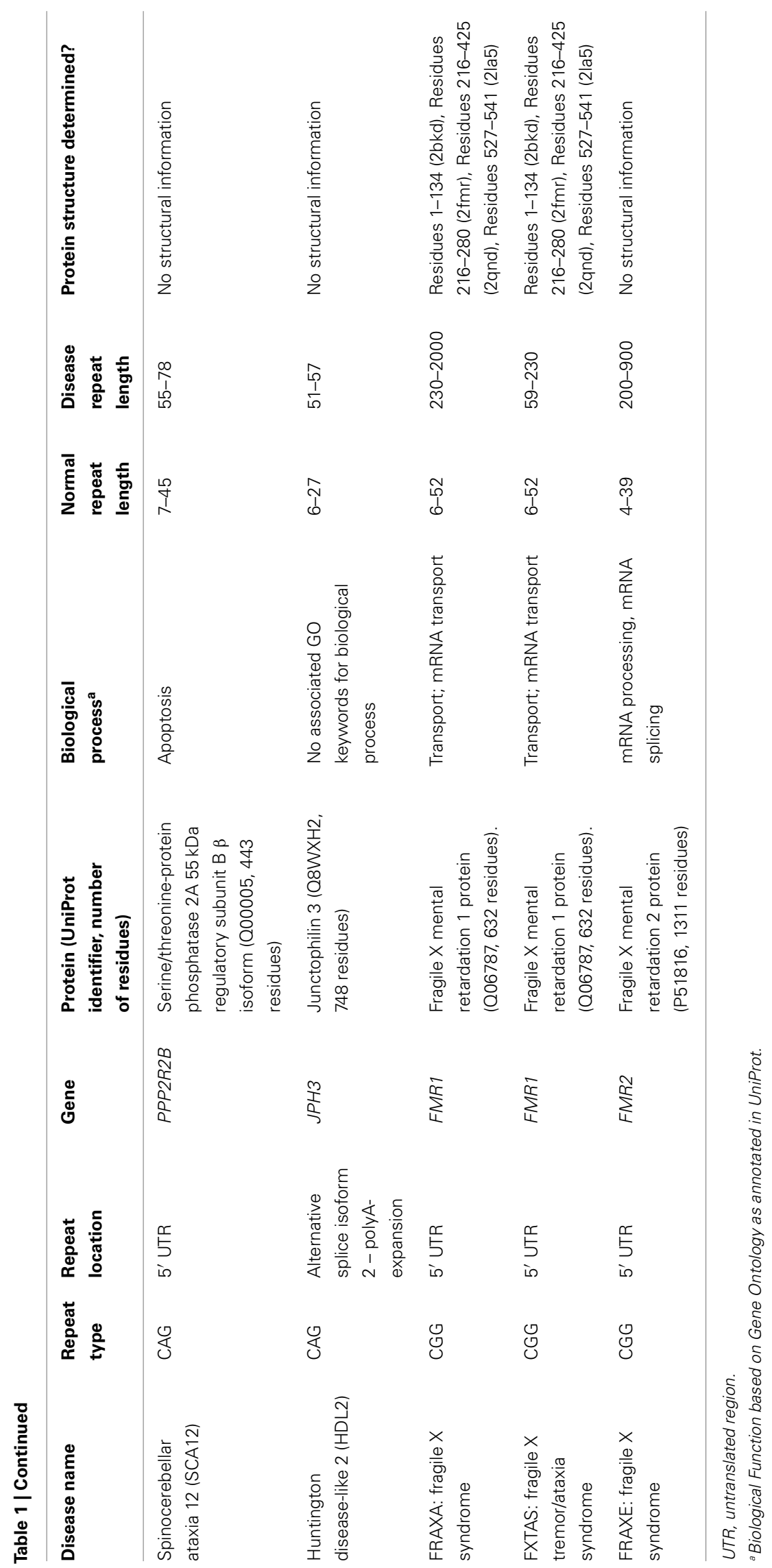




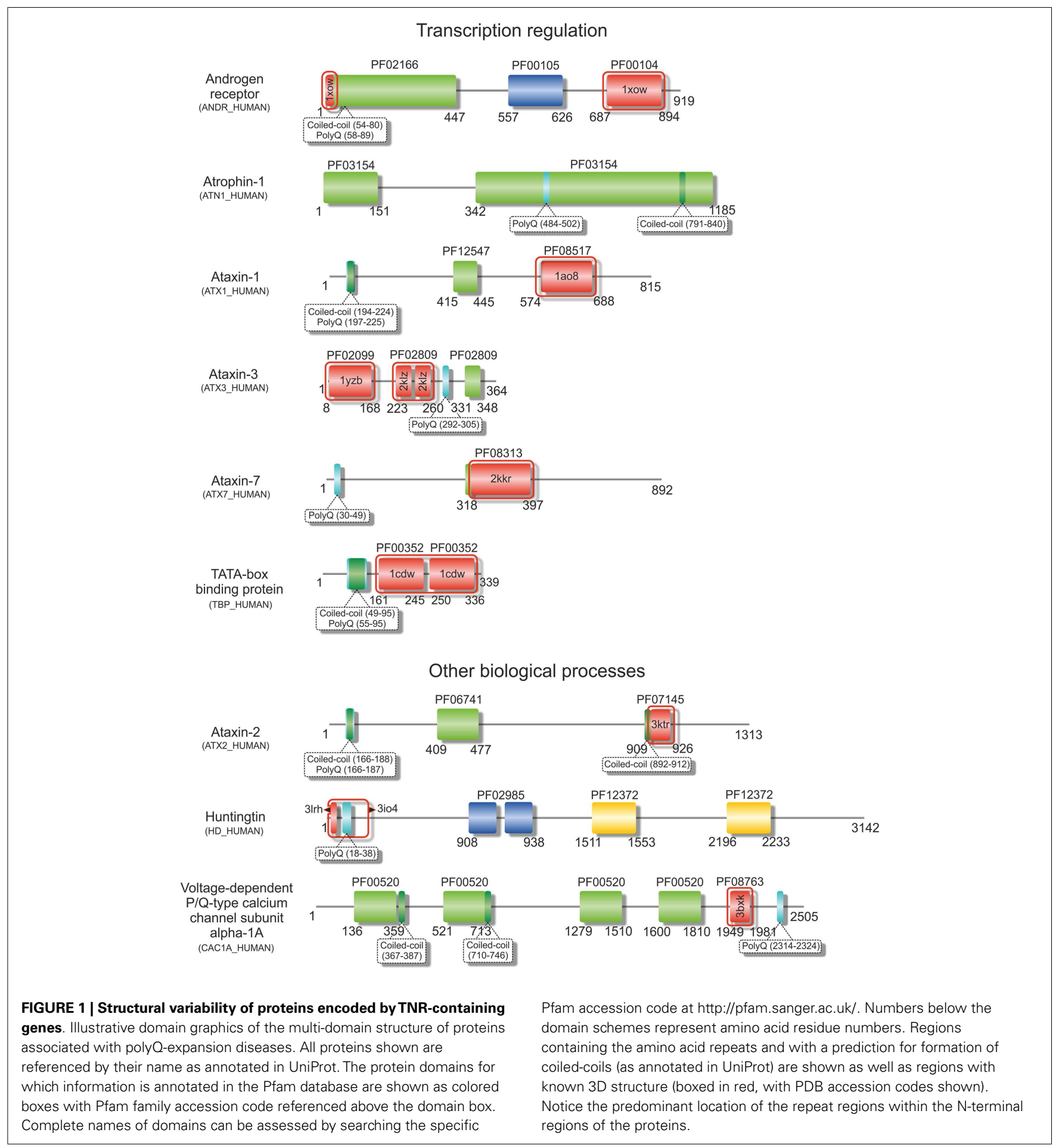

with tandem spaced MBNL1 binding sites were MBNL1 oligomers with a ring-like structure can assemble, possibly leading to the formation of the ribonuclear foci identified in cell models of these TNR diseases (Yuan et al., 2007; de Mezer et al., 2011). The structure and stability of the TNR hairpin structures formed depends on the presence of interruptions as well as on the nature of the flanking regions. This might be related with the ability of individual repeats to participate in the RNA toxicity mechanisms (Krzyzosiak et al., 2012).

In FRDA and FXTAS, pathogenesis results predominantly from decreased expression of the associated genes (FXN and FMR1/FMR2) caused by the expansion of GAA and CGG repeats, respectively, which results in loss of function of key proteins involved in iron-sulfur cluster biogenesis and mRNA translation 


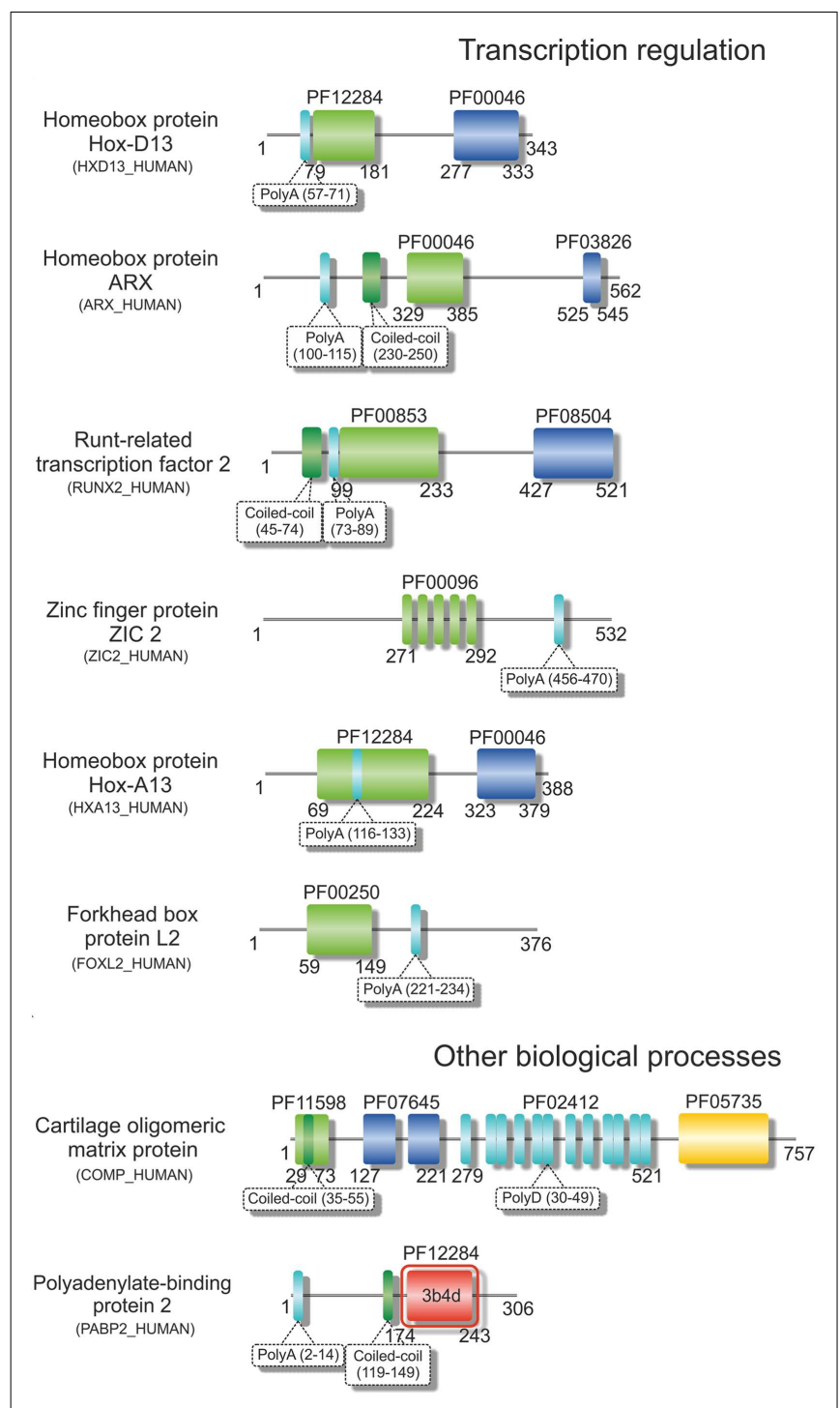

FIGURE 2 | Structural variability of proteins encoded by TNR-containing genes. Illustrative domain graphics of the multi-domain structure of proteins associated with polyD- and polyA-expansion diseases. All proteins shown are referenced by their name as annotated in UniProt. The protein domains for which information is annotated in the Pfam database are shown as colored boxes with Pfam family accession code referenced above the domain box. Complete names of domains can be assessed by searching the specific Pfam accession code at http://pfam.sanger.ac.uk/. Numbers below the domain schemes represent amino acid residue numbers. Regions containing the amino acid repeats and with a prediction for formation of coiled-coils (as annotated in UniProt) are shown as well as regions with known 3D structure (boxed in red, with PDB accession codes shown). Notice the predominant location of the repeat regions within the $\mathrm{N}$-terminal regions of the proteins.

at synapses. Nevertheless, in FXTAS RNA toxicity is also proposed to play a role in pathogenesis ( $\mathrm{Li}$ and Bonini, 2010). The recently discovered mechanisms of pathogenesis in spinocerebellar ataxia type 8 (SCA8) uncovered the extreme complexity of TNR disorders. In fact, SCA8 is caused by expansion of CTG/CAG repeats in the affected gene, which are transcribed bi-directionally leading to the generation of expanded CUG and CAG-containing transcripts further translated into homopolymeric proteins, so that pathogenesis can be mediated by both RNA and protein toxicity (Merienne and Trottier, 2009). Curiously, recent data have highlighted the possibility of non-ATG translation across expanded TNR in all possible reading frames, which might further contribute to the generation of novel toxic proteins and RNAs adding to the multi-parametric character of the pathogenic mechanisms associated with TNR diseases (Li and Bonini, 2010; Pearson, 2011; Sicot et al., 2011).

\section{TRINUCLEOTIDE REPEATS WITHIN PROTEIN CODING REGIONS}

Over 20 years ago, the finding that the expansion of CAG repeats within the coding sequence of the androgen receptor gene was the genetic basis of SBMA (La Spada et al., 1991) represented a hallmark in the discovery of these novel dynamic mutations and their association with human disease. Some years later, the identification of intracellular inclusions containing the expanded proteins (Paulson et al., 1997) provided a clue to pathogenesis, directing research in the field into an extensive search for the mechanisms of polyQ-induced protein aggregation. The moderate expansion of GCG and CAG repeats, which are translated into polyA and polyQ tracts in the affected proteins (Figures 1 and 2), results in protein misfolding and aggregation, in accordance with a general, although not always unique, toxic gain of function mechanism of pathogenesis (Williams and Paulson, 2008). The appearance of insoluble cytoplasmic or nuclear inclusions enriched in the expanded polyA- or polyQ-containing protein constitutes a characteristic fingerprint of these diseases (Messaed and Rouleau, 2009; Orr, 2012a), regardless of their controversial role in pathogenesis. While the proteins containing polyA repeats are predominantly transcription factors with a role in development (see Table 1 and Amiel et al., 2004; Messaed and Rouleau, 2009), most of the proteins linked to polyQ-expansion diseases are involved in DNA-dependent regulation of transcription or neurogenesis and often contain multiple intermolecular partners (Butland et al., 2007). Despite the overall lack of sequence or structural homology, both polyQ- and polyA-repeat expansions are associated with formation of $ß$-rich amyloid-like protein inclusions, and with the wider group of protein misfolding disorders. These inclusions are enriched in ubiquitin, proteasome subunits, and chaperones, and often recruit macromolecules that are part of the macromolecular interaction networks associated with the proteins' native functions (Williams and Paulson, 2008). As an example, the poly(A)-binding protein PABNP1 forms insoluble inclusions upon alanine expansion, co-aggregating together with poly(A)-mRNA, proteasome subunits, ubiquitin, heat-shock proteins, and SKIP, a transcription factor associated with muscle-specific gene expression (Brais, 2003; Tavanez et al., 2009; Winter et al., 2013).

The simplistic view of the predominant role of the inclusions in polyQ-induced pathogenesis was later challenged by the failure of this mechanism to explain the cell-specific vulnerability characteristic for each disease and by the identification of numerous examples of neuronal toxicity in the absence of visible intracellular inclusions (Arrasate et al., 2004). Indeed, the inclusions were shown to be fibrillar and display amyloid-like properties both in vivo and in vitro (Huang et al., 1998; Bevivino and Loll, 2001; 
Sathasivam et al., 2010) and, in a mechanistic parallel with the pathogenic mechanisms proposed for "classical" amyloids, many studies suggested that the insoluble inclusions played a protective role, sequestering toxic, and misfolded protein conformers (Arrasate et al., 2004; Rub et al., 2006; Miller et al., 2010). Indeed, soluble intermediates in the aggregation pathway such as misfolded $\beta$-sheet rich polyQ protein monomers and oligomers have latter been identified and proposed to represent the major toxic species (Kayed et al., 2003; Gales et al., 2005; Nagai et al., 2007; Miller et al., 2011). Also, in OPMD, the primary toxic species are proposed to be the soluble variants of the expanded polyA-repeat protein PABPN1 (Messaed et al., 2007). It is currently accepted that in polyQ disorders the expanded region plays a role in inducing the self-assembly of the carrier protein, which engages in pathogenic interactions and leads to the formation of toxic monomers or oligomers (Takahashi et al., 2008; Weiss et al., 2008) latter converted to insoluble intracellular amyloid-like oligomers where both expanded and "normal" protein are sequestered along with other macromolecular partners (reviewed in Williams and Paulson, 2008; Matos et al., 2011; Costa and Paulson, 2012). As more biochemical data is gathered, more is understood about the role of amino acid expansions in modulating the interaction with macromolecular partners. As an example, expansion of the polyA tract in PABPN1 results in increased association with Hsp70 chaperones and type I arginine methyl transferases (Tavanez et al., 2009). This indicates that the distinct neuropathological features arising from this amino acid-repeat expansion might at least partially result from alterations on the native biological functions and macromolecular interactions of the carrier protein, which might vary in different intracellular environments.

Recent data have shown that expansion of polyA repeats is frequently associated with loss of normal function altering a multitude of cellular pathways with consequences in cell functionality (Amiel et al., 2004; Messaed and Rouleau, 2009), although protein aggregation might also play a dominant role in some of the polyAassociated disorders (Messaed and Rouleau, 2009; Winter et al., 2013). Studies with polyQ proteins have shown that pathogenesis might result from a subtle imbalance in the association of the mutant protein with multiple cellular partners and that toxicity and neuronal death could result from a combination of protein self-assembly and functional alterations (Friedman et al., 2007; Li et al., 2007b; Lim et al., 2008; Kratter and Finkbeiner, 2010; Orr, 2012b; Pastore and Temussi, 2012). In fact, neuronal death as a result of polyQ-expansion seems to resemble that of linker cell in C. elegans (Pilar and Landmesser, 1976; Chu-Wang and Oppenheim, 1978; Blum et al., 2012, 2013) which involves the polyQ protein pqn-4, pointing for a common mechanism for linker cell death, and neuronal death in polyQ diseases (Blum et al., 2013).

Polyglutamine diseases constitute a representative and largely studied group of neurodegenerative disorders where considerable amounts of data have been collected on the role of expanded polyQ for disease pathogenesis. However, given the proposed function of polyQ regions in mediating protein-protein interactions, which might be modulated by polyQ-expansion (Schaefer et al., 2012), the information on the role of these regions for native protein function, structure, and dynamics is still limited. Structural and functional information on the role of these repeat sequences in protein function is crucial to better understand how expansion affects selected neuronal subpopulations. Below, we briefly discuss the current knowledge on the function and structure of polyQ repeats and their role on macromolecular interactions, and finally focus on the known structural and functional information on ataxin-3, the protein whose mutation causes MJD.

\section{FUNCTION OF PolyO ON PROTEIN-PROTEIN INTERACTIONS AND EVOLUTION}

Until recently, the function of many amino acid-repeat-containing proteins and the role of homopeptide regions were somewhat obscure. However, several global analysis studies on single amino acid-repeat-containing proteins shed light onto their function and onto the biological significance of the repeated region, in particular of polyQ, the most prevalent amino acid repetition in humans (Alba and Guigo, 2004). It is now accepted that TNR, particularly those located within protein-coding regions, are considered important mutators providing the genetic variability required for driving evolution (King, 1994; Kashi et al., 1997; Kashi and King, 2006; Nithianantharajah and Hannan, 2007). In fact, simple or low-complexity amino acid-repeats are rare within prokaryotic but extremely abundant within eukaryotic proteins, particularly over-represented in Plasmodium (49-90\% of the total proteome), D. discoideum (52\%), D. melanogaster (20\%), C. elegans (9\%), and H. sapiens (14\%) (Haerty and Golding, 2010). Among all homopolymeric repeats, the most common on eukaryotic proteins are glutamine, asparagine, alanine, and glutamate repeats (Faux et al., 2005). This seems to indicate that there has been a strong negative selection against the appearance of hydrophobic amino acid-repeats with high tendency to aggregate, such as polyisoleucine, polyleucine, polyphenylalanine, and polyvaline (Oma et al., 2005, 2007).

The homopeptide regions seem to be particularly relevant for brain development and function, since these repeated regions can be found in various neurodevelopmental genes (Nithianantharajah and Hannan, 2007). Indeed, the sexual behavior of prairie voles (Hammock and Young, 2005), as well as human pair-bonding (Walum et al., 2008), seems to be dependent on the repeat length in the vasopressin $1 \mathrm{~A}$ receptor gene. A wide study of the distribution and function of homopeptide-containing proteins could also demonstrate a clear trend in humans, D. melanogater, and C. elegans, with the majority of homopeptide-containing proteins performing roles in transcription/translation and signaling processes and to a less extend in transport and adhesion processes (Faux et al., 2005). A similar profile was also found in a comparative analysis of proteins with amino acid-repeats in human and rodents (Alba and Guigo, 2004) and also on a comparative genomic study in domestic dogs, which unveiled an association between morphological variations and the length of the repeated region in the transcription factor-encoded genes ALX4 and RUNX2 (Fondon and Garner, 2004). Analysis of the human genome also revealed the existence of $64 \mathrm{CAG}$ repeat-containing genes involved in biological processes such as regulation of transcription, binding of transcriptional co-activators and transcription factors, and in neurogenesis in general (Butland et al., 2007). Additionally, a detailed analysis of the human polyQ database (http://pxgrid.med.monash. edu.au/polyq/) (Robertson et al., 2011) also indicated that the 
majority of polyQ-containing proteins display domains involved in development (Homeobox domain-containing proteins, Fibroblast growth factor receptor), chromatin remodeling (Bromodomain and PHD-containing proteins), and signal transduction (PDZ domain-containing proteins), all biological processes that are highly dependent on protein-protein interactions and associated with the formation of multicomponent protein complexes. As for humans, analysis of bovine polyQ proteins revealed an enrichment for large multi-domain transcriptional regulators (Whan et al., 2010).

It is currently accepted that the majority of repeat-containing proteins perform roles in processes that require the assembly of large multiprotein or protein/nucleic acid complexes (Faux et al., 2005; Hancock and Simon, 2005; Whan et al., 2010). Supporting this notion is the fact that homopolymeric amino acid-repeats are considered to be unstructured (Gojobori and Ueda, 2011) and that intrinsically unstructured regions are suggested to constitute macromolecular docking sites, which become structured only when bound to cognate ligand partners (Huntley and Golding, 2002; Simon and Hancock, 2009). In fact, "hub proteins" contain significantly longer and more frequent repeats or disordered regions, which facilitate binding to multiple partners (Dosztanyi et al., 2006). Recently, Fiumara et al. (2010) found an overrepresentation of coiled-coils domains in polyQ-containing proteins and in their interaction partners, which are able to form $\alpha$-helical supersecondary structures, often inducing protein oligomerization (Parry et al., 2008). Thus, polyQ tracts due to their intrinsic structural flexibility, which is largely influenced by the flanking residues (see PolyQ: A Simple Sequence Repeat with a Polymorphic Structure below), may act as stabilizers of intra- and intermolecular protein interactions, possibly by extending a neighboring coiled-coil region to promote its interaction with a coiled-coil region in an interacting protein partner (Schaefer et al., 2012). A detailed analysis revealed heptad repeats typical of coiled-coils in regions flanking or overlapping polyQ stretches, whose disruption is sufficient to impair CHIP-huntingtin interaction, indicating that coiled-coils are crucial for polyQ-mediated protein contacts. Importantly, coiled-coils also seem to be important for the regulation of aggregation and insolubility of polyQ-containing proteins (see below and Fiumara et al., 2010) as recently proposed by Petrakis et al. (2012), which discovered a recurrent presence of coiled-coil domains in ataxin-1 misfolding enhancers, while such domains were not present in suppressors.

Based on the several observations on the function of polyQcontaining proteins it is suggested that a general function of polyQ, as for the majority of repeat sequences, is to aid in the assembly of macromolecular complexes, either through tethered distant domains or through interactions with the polyQ itself (Gerber et al., 1994; Korschen et al., 1999; Faux et al., 2005). By affecting protein interactions, and being present in particular functional classes such as transcription factors, polyQ is considered central to the evolution of this type of proteins and consequently crucial to the evolution of cellular signaling pathways (Hancock and Simon, 2005).

A structural analysis of polyQ repeats and its flanking domains as well as its role in protein aggregation will be discussed in greater detail in the next sections.

\section{STRUCTURAL STUDIES ON Poly0 REPEATS}

Since the discovery that polyQ repeats are associated with human neurodegenerative diseases that a huge effort has been made to determine the structure of polyQ and to understand how expansion of the repeat affects the structure of the carrier protein and/or the normal interaction with molecular partners. The first evidence from the aggregation-prone character of polyQ-rich proteins came from studies with glutamine-rich cereal storage proteins and synthetic glutamine polypeptides (Beckwith et al., 1965; Krull et al., 1965). After the discovery that a number of neurological disorders were triggered by expansion of a polyQ tract in different and unrelated proteins (La Spada et al., 1994), and before intracellular inclusions enriched in the polyQ-expanded protein were identified as a major fingerprint in these diseases (Davies et al., 1997; Paulson et al., 1997), Perutz (1994) anticipated that the expanded polyQ tract could mediate protein-protein interactions causing protein aggregation in neurons and recruiting other polyQ-rich proteins such as transcription factors leading to cellular dysfunction. Below, the structural features and self-assembly properties of polyQ sequences are briefly discussed (for a detailed review on the biophysical and structural features of polyQ, see Wetzel, 2012).

\section{Poly0: A SIMPLE SEQUENCE REPEAT WITH A POLYMORPHIC STRUCTURE}

In order to elucidate the structure of the glutamine repeat and to uncover the structural changes induced by polyQ expansion, several strategies have been put forward including (a) the structural analysis of polyQ-containing peptides of different lengths, (b) the characterization of proteins of well-known structure after insertion of an exogenous polyQ repeat, and structural determination of (c) polyQ-antibody complexes, or (d) natural polyQ-rich proteins.

Using synthetic peptides containing 15 glutamine repeats, Perutz and coworkers proposed that polyQ stretches could selfassociate forming hydrogen bonds between their side-chain amide groups and the main chain of a neighboring $\beta$-strand, to form cross- $\beta$ structures (polar zippers) (Perutz, 1994). This study was followed by many reports where synthetic polyQ peptides were used as models of the biophysical properties of polyQ-rich proteins, which established that polyQ-containing peptides have a tendency toward self-assembly into amyloid-like structures (Chen et al., 2002a). Moreover, the results obtained in vitro reflected disease features observed in vivo such as the correlation between larger polyQ size, increased protein aggregation, and earlier disease onset (Chen et al., 2002b; Kar et al., 2011). Circular dichroism studies of polyQ peptides in solution have shown that their monomeric forms lack regular secondary structure (Altschuler et al., 1997; Klein et al., 2007) and additional biophysical experiments proposed that these peptides can adopt collapsed (Crick et al., 2006; Dougan et al., 2009; Peters-Libeu et al., 2012) or extended (Singh and Lapidus, 2008) coils in solution whose compactness was strongly correlated with the polyQ size (Walters and Murphy, 2009). The determination of the structure of monomeric polyQ peptides with atomic detail is however still lacking as a result of their intrinsic conformational flexibility and tendency to aggregate into heterogeneously sized $\beta$-rich oligomers. From the combination of experimental and theoretical methods a picture for polyQ 
structure and aggregation is emerging, where the monomeric polyQ adopt an ensemble of conformations lacking regular secondary structures that assemble into $\beta$-structures in a polyQlength dependent fashion (Vitalis et al., 2009; Walters and Murphy, 2009, 2011; Williamson et al., 2010; Kar et al., 2011). Divergent results proposing the existence of predominantly extended or collapsed conformations or the minimum size for polyQ aggregation are likely due to the differences in the introduction of variable flanking residues (Kar et al., 2011). They might result from the insertion of different polyQ tract interrupting residues (Walters and Murphy, 2011), or be a consequence of the protocols used for the preparation and disaggregation of the peptides used for the biophysical studies (Jayaraman et al., 2011). Most results obtained with these peptides do not generally take into account the possible effects of the protein context on the structural properties of the polyQ stretches, a particularly relevant feature considering that the role of non-polyQ domains in protein aggregation has been reported for ataxin-1 (de Chiara et al., 2005), ataxin-3 (Gales et al., 2005), and huntingtin (Tam et al., 2009; Thakur et al., 2009; Liebman and Meredith, 2010).
In a pioneer work, Stott et al. (1995) inserted a G-Q10$G$ peptide into the inhibitory loop of chymotrypsin inhibitor 2 (CI2), a soluble small protein from barley seeds, showing that this CI2-polyQ chimera has an increased tendency for selfassembly. Even though a CI2 variant with four glutamines crystallized, the structure of the CI2- $\mathrm{Q}_{4}$ dimer showed that the polyQ region was disordered and that oligomerization was mediated by domain swapping (Figure 3A) and not by direct polyQ association (Chen et al., 1999). A structure resembling the proposed polar zipper was later observed between two asparagines in the hinge loop of the major domain swapped dimer of bovine pancreatic ribonuclease A (Liu et al., 2001) (Figure 3B). Insertion of a 10 glutamine repeat within this hinge loop of ribonuclease $\mathrm{A}$, resulted in domain swapping, oligomerization, and amyloid-like fiber formation, but strikingly the enzyme within the fibers was catalytically active, retaining its native fold (Sambashivan et al., 2005). However, although the structure of the domain swapped dimer was solved by X-ray crystallography, the repeat region was not visible in the electron density maps.
A Chymotrypsin inhibitor 2

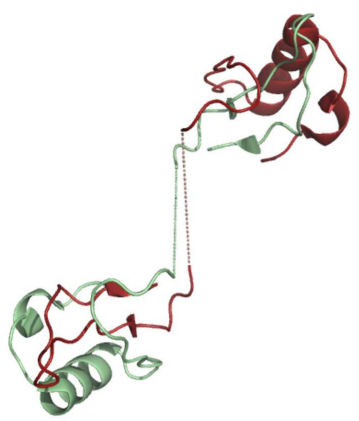

C Antibody : PolyQ peptide complex

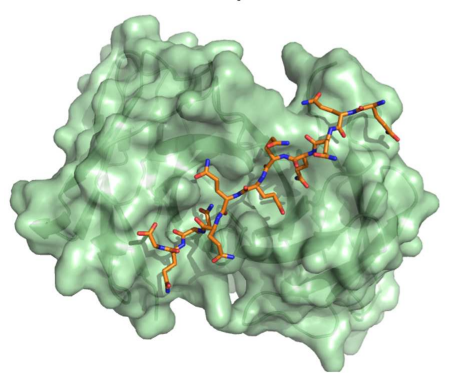

B Ribonuclease A

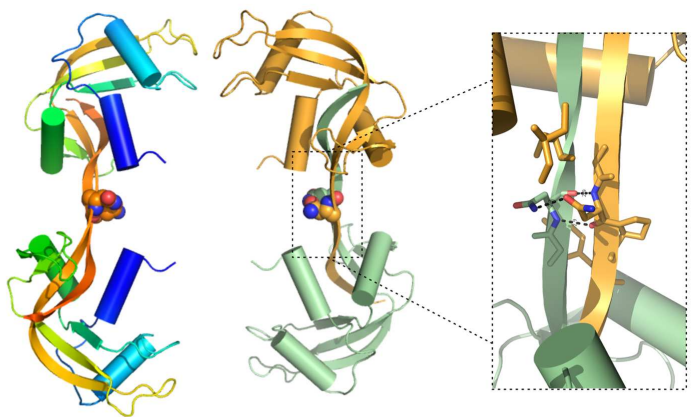

D HDAC4

Q-rich domain

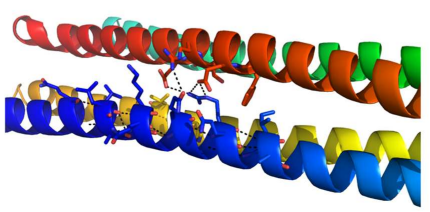

E Huntingtin exon-1 fragments

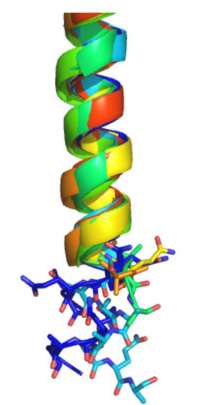

FIGURE 3 | Structure of proteins/protein domains containing polyo regions. (A) Cartoon representation of the domain swapped dimer of chymotrypsin inhibitor 2 with a 4 glutamine insertion [(Chen et al., 1999); PDB accession code $1 \mathrm{cq} 4]$, dotted lines represent the polyQ linker not visible in the X-ray crystal structure. (B) Cartoon representation of domain swapped major dimers of ribonuclease A. Inset shows a short segment resembling the polar zipper formed by asparagine residues in the linker region [(Liu et al., 2001); PDB accession code 1fOv]. (C) Surface representation Fv fragment of a monoclonal antibody in complex with a polyQ peptide shown as sticks [(Li et al., 2007a), PDB accession code 2otu]. (D) Cartoon representation of the glutamine-rich domain from HDAC4 showing details of the polar interactions (dotted lines) at the oligomer interfaces involving glutamine residues [(Guo et al., 2007), PDB accession code 2094]. (E) Cartoon representation of the crystal structures of huntingtin exon-1 fragments observed in different crystal forms, highlighting the different orientations of the C-terminal polyQ residues shown as sticks. The 17 glutamine stretch adopts variable conformations in the structures: $\alpha$ helix, random coil, and extended loop. [(Kim et al., 2009), PDB accession codes 3io4, 3iow, 3iov, 3iou, 3iot, 3ior, 3io6]. 
A first overview of a short polyQ stretch at atomic resolution resulted from the structure of a polyQ 10 peptide $\left(\mathrm{GQ}_{10} \mathrm{G}\right)$ (Figure 3C) bound to MW1, an antibody against polyQ. This structure reveals that polyQ adopts an extended, coil-like structure in which contacts are made between side chains and/or main chain atoms of all 10 glutamines and the antibody-combining site (Li et al., 2007a). The peculiar structural features of these repeatcontaining regions were also revealed by the crystallographic structure of a glutamine-rich domain of human histone deacetylase (HDAC4), that folds into a tetramer-forming straight $\alpha$-helix (Figure 3D). The protein interfaces consist of multiple hydrophobic patches separated by polar interaction networks, in which clusters of glutamines engage in extensive intra- and interhelical interactions (Guo et al., 2007). Further details on the structure of polyQ were unveiled by the high-resolution crystal structures of huntingtin (HD) exon 1, containing 17 glutamines (Htt17Q) (Kim et al., 2009). Htt17Q in fusion with maltose-binding protein (MBP) folds into an amino-terminal $\alpha$-helix followed by a polyQ 17 region that adopts multiple conformations in the different crystal forms, including $\alpha$-helix, random coil, and extended loop, and a polyproline helix formed by the poly $\mathrm{P}_{11}$ and mixed $\mathrm{P} / \mathrm{Q}$ regions (Figure 3E). The authors suggested that the shallow equilibrium between $\alpha$-helical, random coil, and extended conformations can be subtly altered by the size of polyQ sequence, the neighboring protein context, protein interactions, or by changes in cellular environment, and that this polymorphic behavior is a common characteristic of many amyloidogenic proteins (Kim et al., 2009).

\section{SELF-ASSEMBLY AND AGGREGATION OF Poly0 REPEATS}

The first approaches to characterize polyQ-induced protein aggregation and pathogenesis in the context of a full-length protein included the insertion of the polyQ peptides into well-known nonpathogenic protein carriers such as hypoxanthinephosphoribosyl transferase (HPRT), which resulted in a neurological phenotype mimicking that observed in mice expressing the mutant HD truncated protein (Ordway et al., 1997). In vitro studies aiming at better characterizing the structure and function of polyQ repeats in the context of full-length soluble proteins, included the insertion of ectopic polyQ stretches into well-characterized and soluble proteins such as CI2 (Stott et al., 1995; Chen et al., 1999), myoglobin (Mb) (Tanaka et al., 2001; Tobelmann and Murphy, 2011), glutathione S transferase (GST) (Masino et al., 2002; Bulone et al., 2006) and the B domain from Staphylococcus aureus Protein A (SpA) (Saunders et al., 2011). Fusion of the polyQ sequences with stable and soluble proteins moderates the intrinsic polyQ peptide aggregation propensity, but induces the self-assembly of carrier proteins into fibrillar amyloid-like structures, a nucleationdependent process whose kinetics is directly proportional to the size of the inserted polyQ repeat. Likewise, polyQ peptides are able to seed the aggregation of intracellular soluble polyQ-containing proteins when added to cell cultures, conferring a heritable phenotype of self-sustaining seeding, resembling a prion-like mechanism (Ren et al., 2009), reviewed in Cushman et al. (2010).

The impact of the polyQ tract and its expansion on the perturbation of the structure of flanking sequences and domains is critically dependent on the location of the amino acid-repeats, revealing impressive location-dependent changes in structural stability, and fibril morphology of the host proteins (Robertson et al., 2008; Saunders et al., 2011; Tobelmann and Murphy, 2011). Curiously, the studies with these model proteins showed that stability and structure of the carrier protein remained unaltered by polyQ expansion when the repeat was inserted at the $\mathrm{N}$ - or C-terminus of the structured domain (Robertson et al., 2008), mimicking the location of polyQ tracts in most disease-related proteins (Figure 1).

The role of the flanking regions in modulating protein fibril formation in polyQ disease proteins is well supported by experimental data (de Chiara et al., 2005; Gales et al., 2005; Bhattacharyya et al., 2006; Saunders and Bottomley, 2009; Tam et al., 2009; Thakur et al., 2009; Liebman and Meredith, 2010), in agreement with the knowledge that different polyQ-containing proteins have a diverse threshold for aggregation. For example, addition of a polyproline extension after the polyQ repeat slows down aggregation (Bhattacharyya et al., 2006), while protein domains outside the polyQ tract [e.g., Josephin domain (JD) of ataxin-3 and AHX domain of ataxin-1] have been shown to contribute to protein aggregation (Masino et al., 2004; de Chiara et al., 2005; Gales et al., 2005; Ellisdon et al., 2006, 2007). The multitude of data on the polyQ-induced aggregation of disease and non-disease-proteins highlights the complex interplay between the polyQ region and the adjacent protein domains. In light of the polymorphic nature of the polyQ and the modulation of its structural features by the protein context, two general mechanisms have been proposed for polyQ-mediated toxicity (Kim et al., 2009): (a) the expanded polyQ stretch adopts a novel conformation that mediates toxicity or is the precursor to toxic species; (b) intra- or intermolecular protein interactions mediated by expanded polyQ in the random coil conformation are sufficient to result in pathological effects. In both cases the affinity of the interactions involving the expanded polyQ region could be higher with selected target proteins, leading to a preference of the disease proteins for some of the protein partners, a fact that is in agreement with the hypothesis raised by Zuchner and Brundin (2008), which postulate that resistance to NMDA receptor-mediated excitotoxicity occurring in some mouse models for HD is a consequence of a differential binding of partner proteins, in a polyQ tract size dependent manner, to the proline-rich domain of huntingtin. In this context, differences in molecular interactions occurring in a cell- and tissue-specific manner would result in different toxicities according to particular cellular environments.

Given the above mentioned studies, it is nowadays clear that the polyQ region influences aggregation of proteins, but this process is highly dependent on the surrounding protein context. Therefore, even though the structural information on peptides and proteins with polyQ expansions is a useful guideline for the investigation of the pathogenic effects of polyQ expansion, each of the proteins involved in polyQ diseases shows distinctive characteristics, cellular roles, and structural properties causing difficulties in the formulation of structural hypothesis that could explain how different monomeric conformations of polyQ leads to various aggregated species and how they contribute to neurotoxicity. 


\section{Poly0 REPEATS IN ATAXIN-3 FUNCTION AND DYSFUNCTION} Machado-Joseph disease is an inherited neurodegenerative disorder of adult onset originally described in people of Portuguese Azorean descent but later shown to be the most common autosomal dominant spinocerebellar ataxia worldwide. Clinically, it is characterized by ataxia, ophthalmoplegia, and pyramidal signs, associated in variable degree with dystonia, spasticity, peripheral neuropathy, and amyotrophy (Coutinho and Andrade, 1978). Pathologically, the disorder is associated with degeneration of the deep nuclei of the cerebellum, pontine nuclei, subthalamic nuclei, substantia nigra, and spinocerebellar nuclei (Coutinho et al., 1982; Rosenberg, 1992; Margolis and Ross, 2001). It is caused by an expansion of a repetitive CAG tract within the ATXN3 gene (Kawaguchi et al., 1994). While in the healthy population the number of CAG repeats ranges between 10 and 51, in MJD patients the length of ataxin-3 polyQ tract exceeds 55 consecutive residues. Ataxin-3 is a modular protein, located both in the nucleus and the cytoplasm (Perez et al., 1999; Antony et al., 2009; Macedo-Ribeiro et al., 2009), encompassing an N-terminal globular JD, with structural similarity to cysteine proteases (Scheel et al., 2003; Albrecht et al., 2004), followed by an extended tail composed of two ubiquitin interaction motifs (UIMs), the expandable polyQ tract, and a C-terminal region (Matos et al., 2011). The C-terminal region of ataxin-3 may contain a third UIM, depending on the splice variant (Goto et al., 1997), with the 3UIM isoform of ataxin-3 being predominantly found in the brain (Harris et al., 2010). Currently, the physiological function of ataxin-3, as well as the molecular mechanism by which expanded polyQ sequences causes selective neurodegeneration remain mostly unknown. However, since it is ubiquitously expressed and cell death is region specific, neurodegeneration is currently viewed as depending on sequence and structural features outside the ataxin-3 polyQ tract [reviewed in Matos et al. (2011) and references therein].

\section{ATAXIN-3 BIOLOGICAL ROLES}

ATXN3 orthologs have been identified in eukaryotic organisms including protozoans, plants, fungi, and animals (Albrecht et al., 2004; Costa et al., 2004; Rodrigues et al., 2007). Several functions have been ascertained to ataxin- 3 based on studies with orthologs. Specifically, a role in cell structure and/or motility was proposed for mouse ataxin-3 as it is highly abundant in all types of muscle and in ciliated epithelial cells (Costa et al., 2004). In fact, ataxin-3 is able to interact with tubulin through its JD domain (Figure 4), with $\mathrm{nM}$ affinity (Mazzucchelli et al., 2009), which supports a role in cell structure. Interestingly, data on ataxin-3 C. elegans ortholog not only reinforces a function in structure/motility and signal transduction (Rodrigues et al., 2007), but also indicate a function in development as absence of ATXN3 strongly modifies expression of several development-related genes. ATXN3 knockout animals showed no obvious deleterious phenotype, probably due to a putative redundant function between ataxin-3 and other JD-encoding proteins, such as ataxin-3-like protein, Josephin 1 and Josephin 2, all containing a typical cysteine protease catalytic triad. However the studies with ATXN3 knock-out animals revealed an overall increase in the levels of ubiquitinated proteins (Schmitt et al., 2007) and signs of altered expression of core sets of genes associated with the ubiquitin-proteasome and signal transduction pathways (Rodrigues et al., 2007), pointing to a dual function of ataxin-3 in the ubiquitin-proteasome system and transcriptional regulation (Matos et al., 2011; Orr, 2012a).

\section{Ataxin-3 function as transcriptional regulator}

The putative role of ataxin-3 in transcriptional regulation is proposed to entail the modulation of histone acetylation and deacetylation at selected promoters. Ataxin-3 interacts with the major histone acetyltransferases cAMP-response-element binding protein (CREB)-binding protein (CBP), p300, and p300/CREBbinding protein-associated factor (KAT2B/PCAF, Figures 4 and 5), and is proposed to inhibit transcription in specific promoters (e.g., MMP-2 promoter) either by blocking access to histone acetylation sites or through recruitment of histone deacetylase 3 (HDAC3) and nuclear receptor co-repressor (NCOR1; Figures 4 and 5) (Li et al., 2002; Evert et al., 2006). Although, the interaction sites have not been mapped in detail for all these proteins, co-immunoprecipitation experiments showed that KAT2B/PCAF, p300, and CBP bind exclusively to the polyQ-containing Cterminal region of ataxin-3 (Figure 4), apparently in a polyQ-size dependent manner (Li et al., 2002). Experimental evidence also indicates that ataxin-3 forms part of a CREB-containing complex, although no direct interaction has been observed between the two proteins ( $\mathrm{Li}$ et al., 2002). In contrast, the $\mathrm{N}$-terminal region of ataxin-3 directly binds histones $\mathrm{H} 3$ and $\mathrm{H} 4$ (Table 2; Figure 4) (Li et al., 2002). Of note, p300 and CBP, as well as NCOR1, also encompass amino acid repetitions in its sequence. Interestingly, in huntingtin and in ataxin-1, polyQ interferes with CBPactivated gene transcription via interaction of their glutaminerich domains (Shimohata et al., 2000; Nucifora et al., 2001) and mutant huntingtin targets specific components of the core transcriptional machinery, in a glutamine-tract length-sensitive manner (Zhai et al., 2005), pinpointing once again the role of the amino acid-repeat region in the establishment of protein-protein interactions.

\section{Ataxin-3 molecular function: ubiquitin hydrolase}

A role for ataxin-3 in ubiquitin-dependent pathways was proposed by bioinformatic analysis (Scheel et al., 2003; Albrecht et al., 2004), and its ability to bind and cleave poly-ubiquitin chains and polyubiquitinated proteins was later demonstrated experimentally (Burnett et al., 2003; Chai et al., 2004). Importantly, inhibition of ataxin-3 catalytic activity results in the increase of polyubiquitinated proteins, resembling the effects of proteasome inhibition (Berke et al., 2005), indicating that ataxin-3 is involved with proteins targeted for proteasomal degradation. The function of ataxin- 3 in the ubiquitin-proteasome system was further supported by the identification of its association with the ubiquitin-like domain of the human homologs of the yeast DNA repair protein Rad23, HHR23A, and HHR23B (Wang et al., 2000; Doss-Pepe et al., 2003; Nicastro et al., 2005, 2009), with valosincontaining protein (VCP)/p97 (Hirabayashi et al., 2001; Doss-Pepe et al., 2003; Boeddrich et al., 2006; Zhong and Pittman, 2006), and with the ubiquitin ligase E4B (Matsumoto et al., 2004) (Figures 4 and 5). Strikingly, the weak direct association between ataxin-3 and $\mathrm{E} 4 \mathrm{~B}$ is strongly reinforced by the addition of $\mathrm{VCP} / \mathrm{p} 97$, indicating that these proteins form part of a higher order macromolecular 


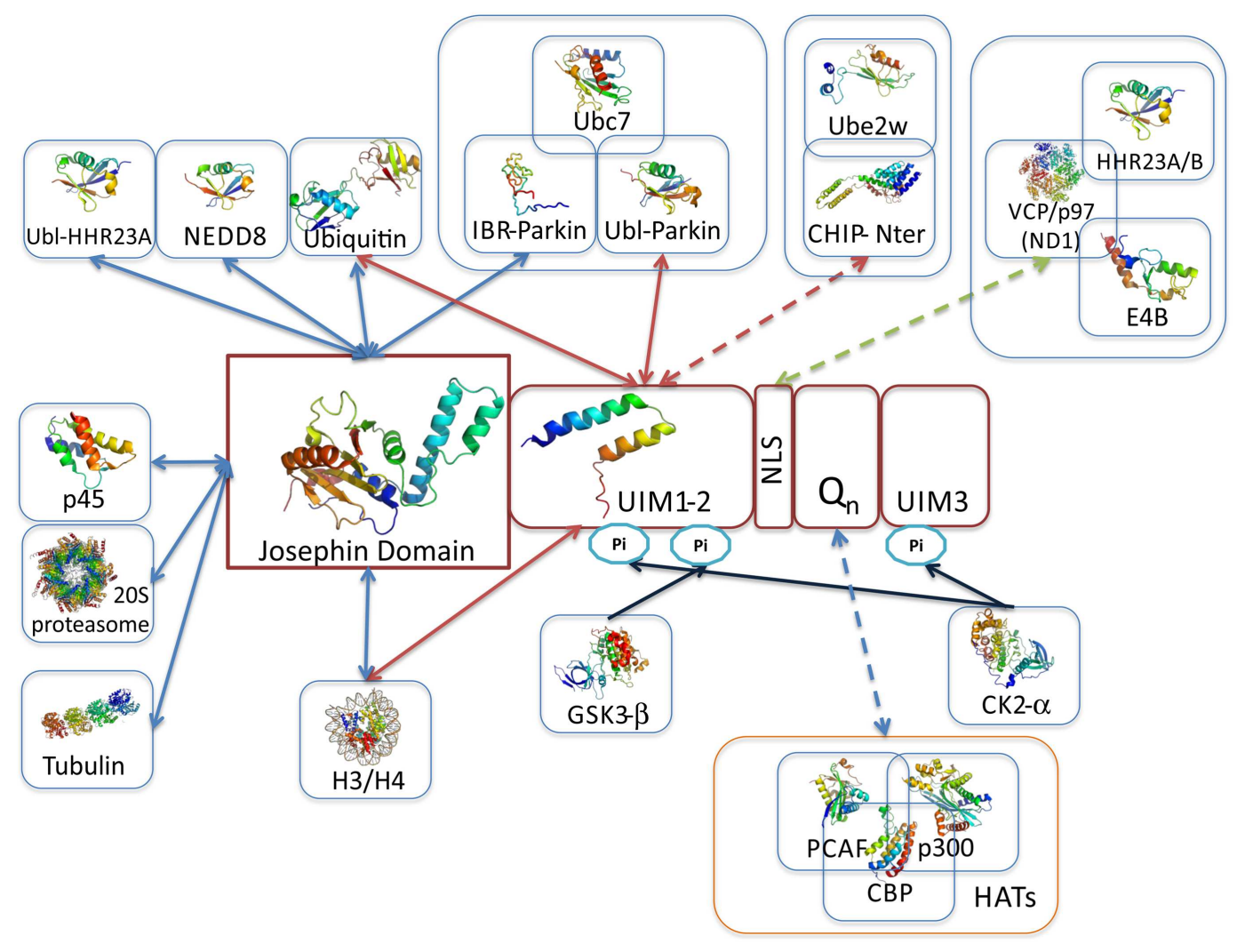

FIGURE 4 | Overview of ataxin-3 structural information. Schematic illustration of ataxin-3 (isoform 2; a.k.a. 3UIM isoform) domain structure highlighting the regions involved in protein-protein interactions. The solution structures of the Josephin domain (PDB accession code 1yzb) and UIMs1-2 (PDB accession code $2 \mathrm{klz}$ ) are shown colored from $\mathrm{N}$-(blue) to $\mathrm{C}$ - terminus (red). JD-, UIM-, NLS-, and polyQ-mediated interactions are represented by blue, red, green, and purple arrows, respectively; blue arrows indicate the location of post-translational modification sites, resulting from the interaction and phosphorylation by CK2 and GSK3. Representative multi-subunit

complexes where ataxin-3 participates are boxed (Li et al., 2002; Matsumoto et al., 2004; Scaglione et al., 2011; Durcan et al., 2012). One of the main questions in the quest for ataxin-3 interacting proteins is whether polyQ-expansion of the disease-protein modulates the binding affinities. Current data indicates that polyQ-expansion increments the ataxin-3 affinity for CHIP (Scaglione et al., 2011), VCP/p97 (Matsumoto et al., 2004; Boeddrich et al., 2006; Zhong and Pittman, 2006), and the transcription regulators p300, CBP, and PCAF (Li et al., 2002) (interactions represented by broken lines). Strikingly, all these interactions are mediated by ataxin-3 flexible tail, which includes the polyQ tract. Moreover the transcriptional regulators p300, CBP, and NCOR all contain amino acid repeats. complex to regulate the degradation of misfolded ER proteins (Matsumoto et al., 2004; Zhong and Pittman, 2006) (Figure 5).

Biochemical studies showed that ataxin-3 displays a strong preference for chains containing four or more ubiquitins (Chai et al., 2004) and that full-length ataxin-3 and its JD both display proteolytic activity toward either linear substrates containing a single ubiquitin molecule (Burnett et al., 2003; Chow et al., 2004b; Weeks et al., 2011) or K48/K63-linked poly-ubiquitin chains (Winborn et al., 2008; Todi et al., 2009), displaying also the capacity to bind the ubiquitin-like protein NEED8 in a substrate-like fashion (Ferro et al., 2007). Moreover, ataxin-3-like protein, Josephin 1 and Josephin 2, also display ubiquitin protease activity (Tzvetkov and Breuer, 2007; Weeks et al., 2011), although the relative activities are highly variable in spite of their high sequence similarity. Characterization of ataxin-3 ubiquitin hydrolase activity has also revealed that the full-length protein preferentially cleaves Lys-63-linked and mixed-linkage chains with more than four ubiquitins (Burnett et al., 2003; Winborn et al., 2008). This specificity is dictated by the UIMs, as the isolated JD shows a preference toward the disassembly of Lys-48-linked chains (Nicastro et al., 2009, 2010). Altogether, this indicates that ataxin-3 ubiquitin hydrolase activity is likely to be associated with delivery of target substrates to the proteasome rather than with their rescue from degradation, as it happens with most of the other deubiquitinases (Ventii and Wilkinson, 2008; Matos et al., 2011; Scaglione et al., 2011). Interestingly, ubiquitin hydrolase activity of ataxin-3 is not affected by polyQ expansion and both normal and expanded ataxin-3 are able to increase the cellular levels of a short-lived GFP normally degraded by the ubiquitin-proteasome pathway (Burnett et al., 2003).

The 3D structures for JD alone or in the presence of ubiquitin as well as that of the tandem UIM1-UIM2 have already been determined (Mao et al., 2005; Nicastro et al., 2005, 2009; Song et al., 2010), giving a structural perspective on the ubiquitin hydrolase function of ataxin-3. The JD contains two ubiquitin binding sites, both of hydrophobic nature, with site 1 being negatively charged to 


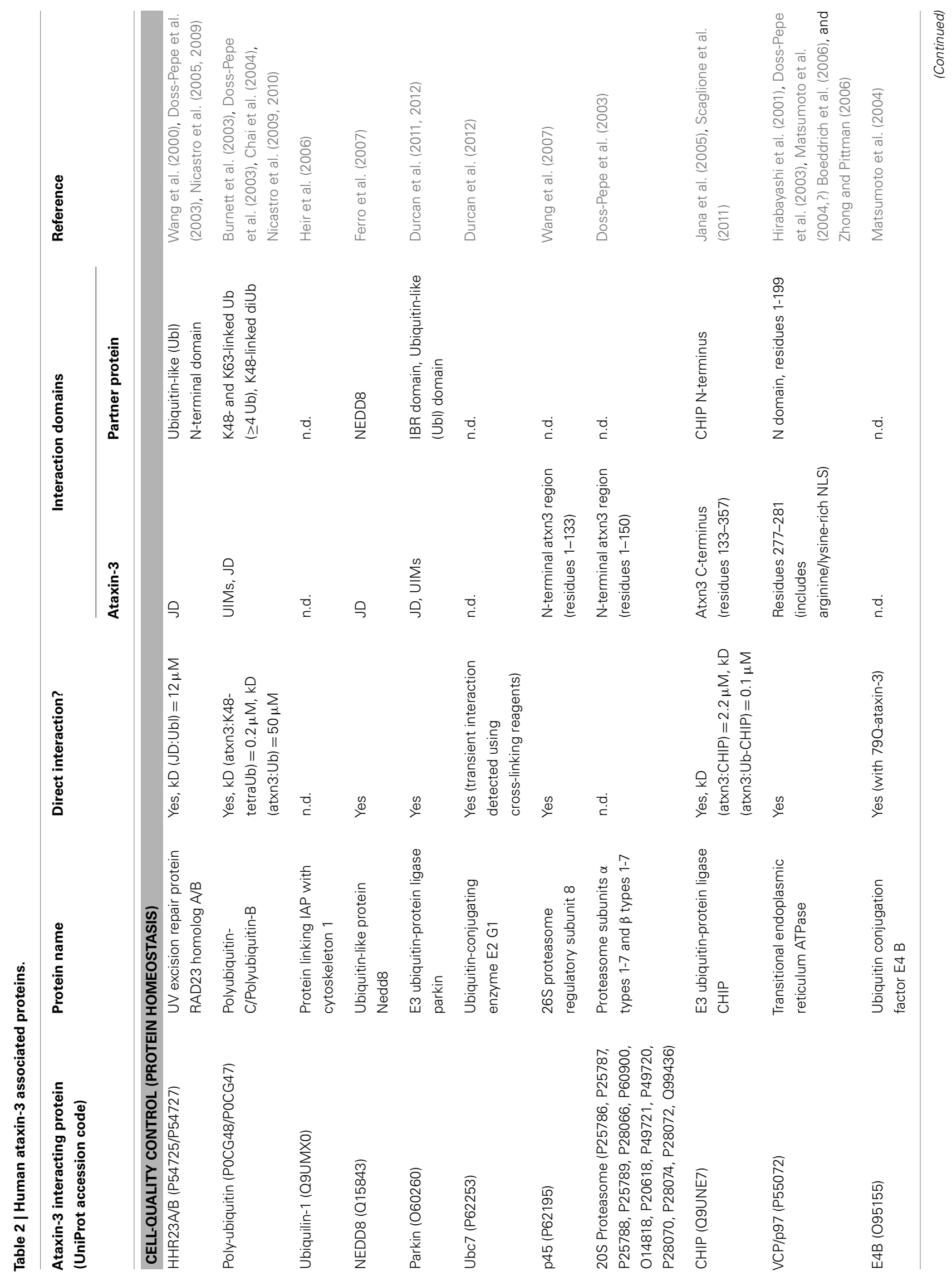




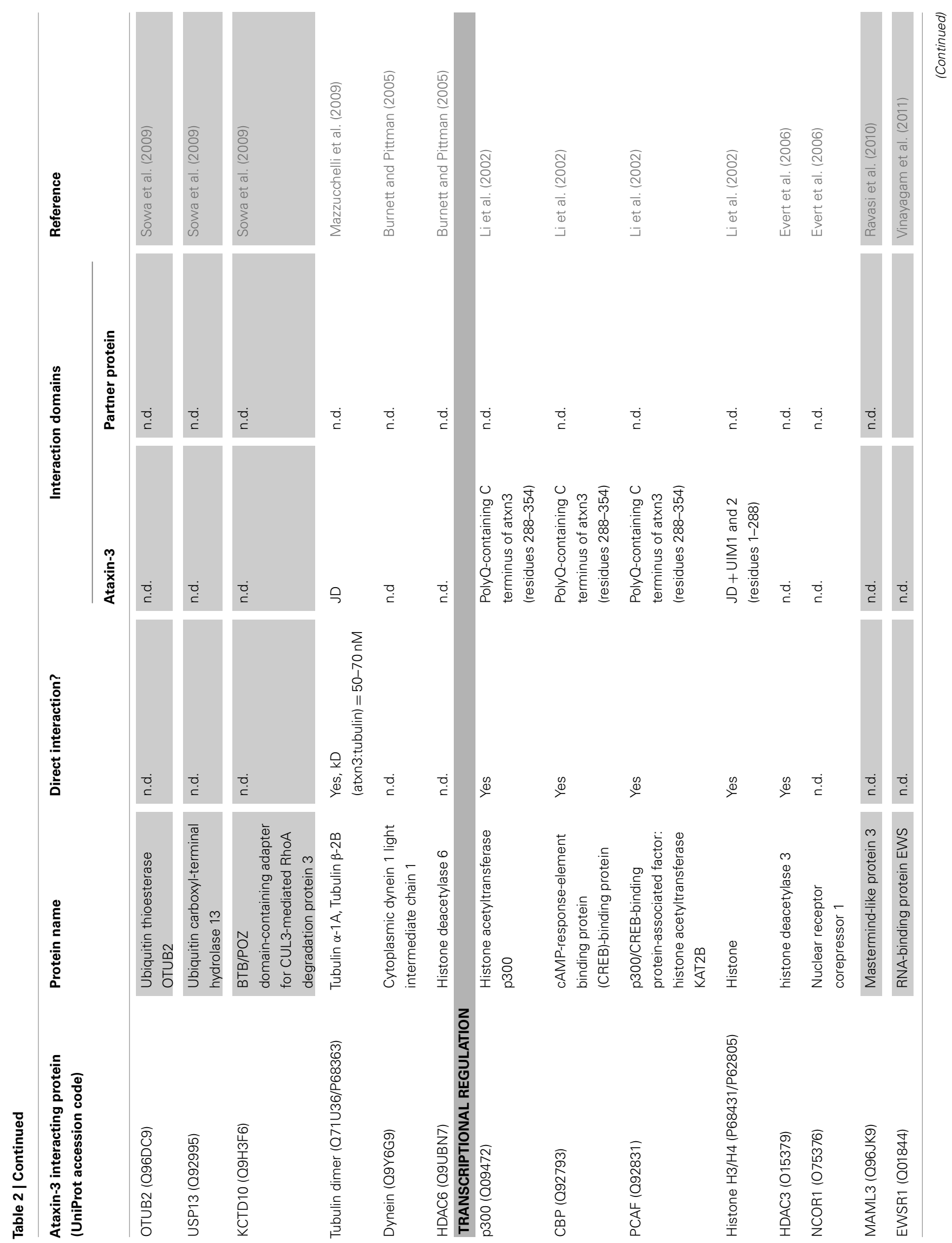




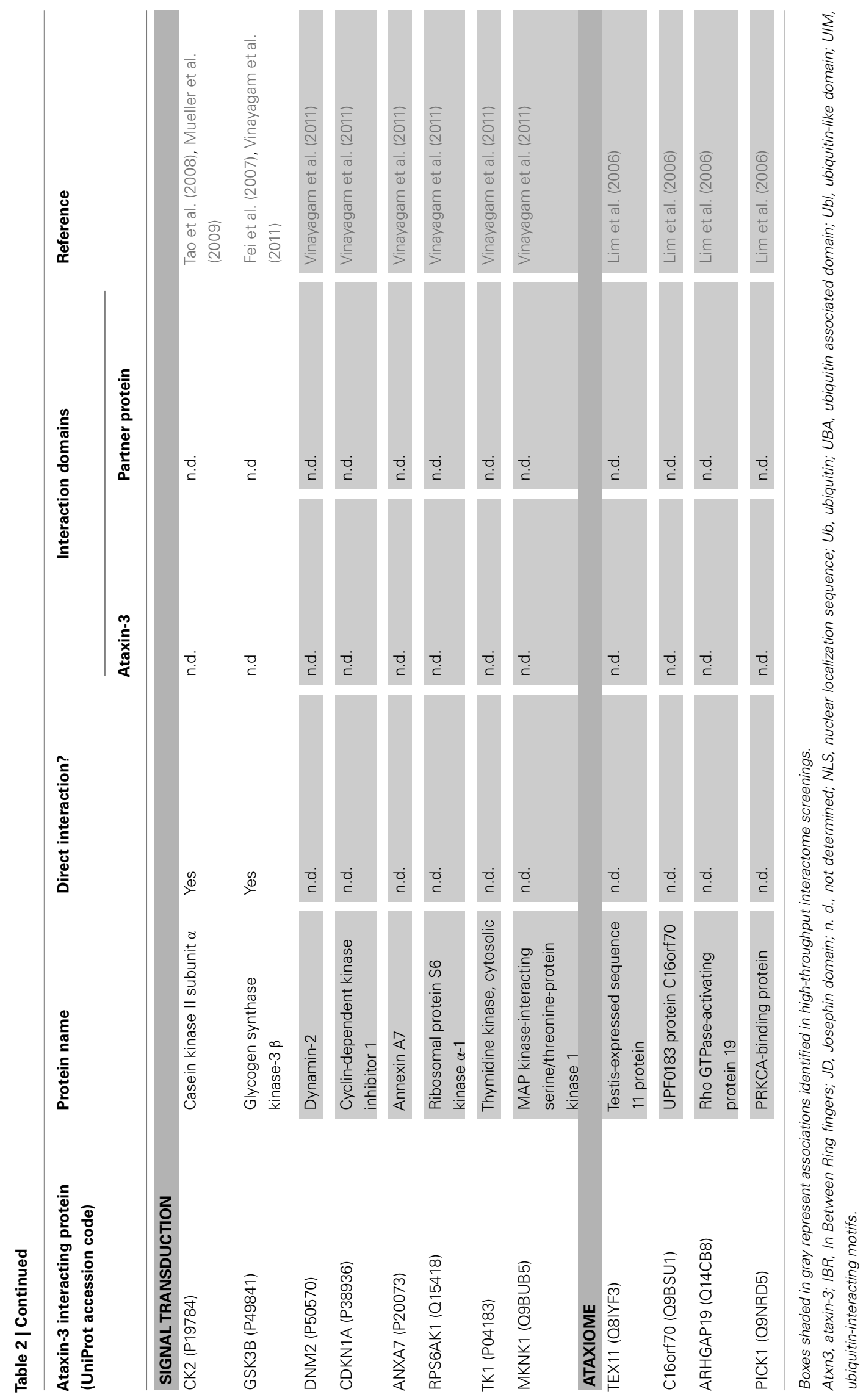




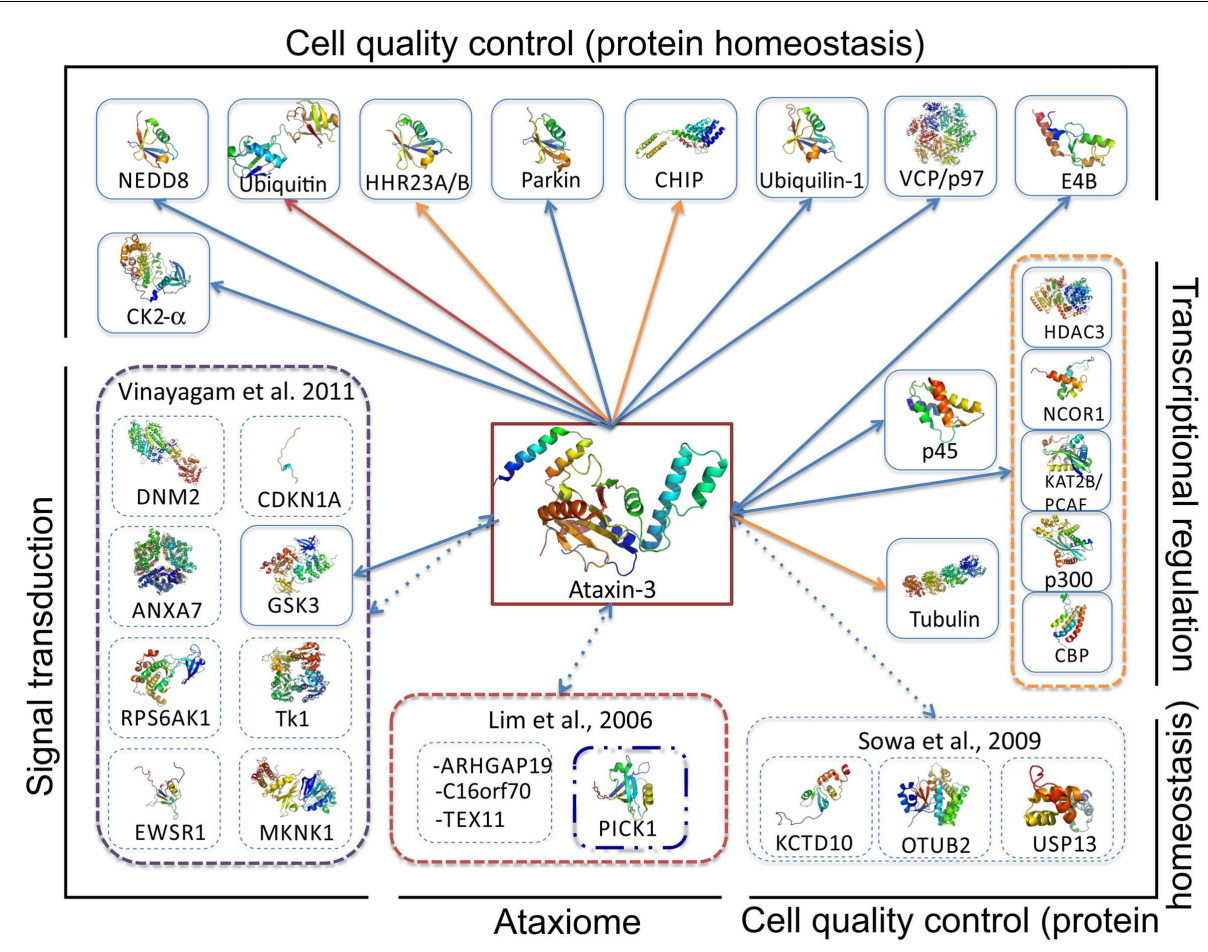

FIGURE 5 | Overview of ataxin-3 protein interaction network. Data on the ataxin-3 interactors was obtained by analysis of Interactome3D (Mosca et al., 2012), MINT (Ceol et al., 2010), and Dr. PIAS (Sugaya and Furuya, 2011) protein interaction databases, and completed with data compiled from current literature on ataxin-3 protein associations obtained with a diverse set of experimental approaches (see complete information on
Table 2). Red arrows indicate interactions for which structural data has been obtained, while orange arrows indicate that biophysical data on interaction affinity in vitro is known (Table 2). Broken arrows represent interactions that result from high-throughput interactome analysis that still require detailed biochemical and functional analysis. Proteins are grouped according to their biological role. facilitate docking of the positively charged ubiquitin C-terminus close to the catalytic site. Binding of ubiquitin to site 1 is of crucial importance for both JD and full-length ataxin-3 activity as ubiquitin hydrolase (Nicastro et al., 2010). Site 2 confers ubiquitin-chain linkage preference to ataxin-3 and it overlaps with the surface for interaction of the ubiquitin-like domain in HHR23B (Nicastro et al., 2005, 2010). Solution structure for the two UIMs (UIM1 and UIM2), which are separated by a short 2 amino acid spacer, revealed that they fold into two $\alpha$-helices separated by a flexible linker (Song et al., 2010). Upon ubiquitin binding, this structure adopts a typical helix-loop-helix folding pattern, where hydrophobic interactions dominate the complex formation (Song et al., 2010). When in tandem, UIM1 and UIM2 show higher binding affinity for mono- or poly-ubiquitin than individual UIMs (Song et al., 2010), suggesting a cooperative binding mechanism (Song et al., 2010). The effect of the presence of UIM3 in ataxin-3 binding affinity for ubiquitin has not been shown, but its role in ubiquitin chain binding and recognition is unlikely to be of relevance to ataxin-3 activity, since no differences in proteolytic activity were identified when the 2UIM and 3UIM isoforms were compared. In the model proposed for ataxin-3 ubiquitin chain proteolysis, the UIMs (UIM1-UIM2) select and recruit poly-ubiquitin substrates, presenting them to the catalytic JD for cleavage (Mao et al., 2005).

Even though ataxin-3 functions as ubiquitin hydrolase, its proteolytic activity is rather low, indicating that either ataxin-3/JD requires additional factors (post-translational modifications, cofactors, intracellular interactions) to exhibit significant proteolytic activity or the substrates used in vitro so far are not optimal. Interestingly, only three amino acid mutations are sufficient to significantly increase the proteolytic activity of ataxin-3, to a value close to that of ataxin-3-like protein (Weeks et al., 2011). Under physiological conditions, one candidate for an activating signal is mono-ubiquitination at $\mathrm{K} 117$, which has been shown to increase the enzyme's rate of cleavage of Lys-63 linked substrates (Todi et al., 2009). However, the molecular mechanism by which ubiquitination increases enzyme activity is not still clear, nor is it known whether other cellular signals (e.g., phosphorylation by CK2 or GSK3b; Fei et al., 2007; Tao et al., 2008) may also modulate the activity of ataxin-3. Interestingly the JDcontaining protein, Josephin 1 was also demonstrated to cleave ubiquitin chains only after it is mono-ubiquitinated (Seki et al., 2013). The regulation of ataxin-3 activity through ubiquitination might depend on the interaction of ataxin-3 with several E3 ubiquitin ligases (Durcan and Fon, 2013), such as the C-terminus of $70 \mathrm{kDa}$ heat-shock protein (Hsp70)-interacting protein (CHIP), parkin, and E4B (Figure 5), since all were shown to promote ataxin-3 ubiquitination and regulate its degradation by the proteasome (Matsumoto et al., 2004; Jana et al., 2005; Miller et al., 2005). Association of ataxin-3 with CHIP is a multistep process regulated by mono-ubiquitination of the $\mathrm{N}$-terminal region of 
CHIP by the E2-conjugating enzyme Ube2w, and occurs through the region encompassing polyQ and UIM1 and 2 (Jana et al., 2005) (Figure 4). As observed for other interactions involving the C-terminal region of ataxin-3, the ataxin-3-CHIP complex is affected by polyQ expansion and the polyQ-expanded protein displays a sixfold increase in binding affinity (Scaglione et al., 2011). The presence of ataxin-3 in multicomponent E3-ligase complexes is also supported by the identification of a direct interaction with parkin, an association that stabilizes the interaction between parkin and the E2-conjugating enzyme Ubc7 (Durcan et al., 2011). In contrast with what is observed in the ataxin-3:CHIP complex, ataxin-3 association with parkin remains unaltered by polyQ expansion (Durcan et al., 2012) (Figure 4). However, we still do not understand the mechanisms that regulate shuttling of ataxin3 between these functional complexes or how its distribution is modulated by polyQ expansion. Further biochemical studies are required to establish the correlation between these macromolecular interactions and their relevance for ataxin-3 aggregation and neurodegeneration in MJD patients

\section{ATAXIN-3 AGGREGATION: A MULTISTEP PATHWAY MODULATED BY THE PROTEIN CONTEXT}

A characteristic hallmark of MJD and other polyQ-expansion diseases is the appearance of intracellular inclusions enriched in the disease protein and containing components from the cellquality control machinery (e.g., ubiquitin, proteasome subunits, and chaperones), indicating that these diseases form part of the larger family of protein misfolding disorders (Williams and Paulson, 2008). Early in vitro studies showed that expansion of the polyQ tract within the pathological range induced formation of insoluble $\beta$-rich fibrils with the capacity to bind amyloidspecific dyes (Bevivino and Loll, 2001). Later it was demonstrated that non-pathological ataxin-3 could also form insoluble fibrillar aggregates upon destabilization of its structure by temperature, pressure or denaturing agents (Marchal et al., 2003; Chow et al., 2004c). Unexpectedly, under partially destabilizing conditions the JD was also able to form insoluble fibrils, indicating that even though polyQ repeats are themselves toxic, the structure of ataxin3 , besides polyQ, has an important role in aggregation and fibril formation (Masino et al., 2004). Structural studies have shown that in ataxin-3, the addition of a polyQ tract destabilized the protein but polyQ expansion within the pathogenic range did not further induce significant structural changes (Chow et al., 2004a). In fact, alterations in ataxin-3 stability were later shown not to be a requirement for amyloid fibril formation since both non-expanded ataxin-3 and the isolated JD were shown to selfassemble and form fibrils under near-physiological conditions (Gales et al., 2005). Since kinetics of aggregation is slower for non-expanded ataxin-3 (Ellisdon et al., 2007), early events in the oligomerization pathway could be identified, with the formation of JD-mediated dimers proposed to be the first step in the ataxin-3 self-assembly pathway (Gales et al., 2005; Masino et al., 2011; Scarff et al., 2012). In a striking parallel with the classical amyloids the kinetics of fibril formation follows a nucleation-dependent polymerization mechanism, where these intermediate species might represent the most toxic species (Kayed et al., 2003; Laganowsky et al., 2012).
The current model for polyQ-expanded ataxin-3 aggregation consists of two steps. A JD-dependent step that leads to the formation of SDS-soluble protofibrils, followed by the formation of detergent-resistant fibrils similar to those found in MJD, where the polyQ-expanded tracts play a key role (Ellisdon et al., 2006, 2007). On the contrary, non-expanded polyQ ataxin-3 undergoes a single step aggregation event resulting in SDS-soluble aggregates, which does not involve the polyQ tract (Ellisdon et al., 2006) but directly depends on conformational changes outside the polyQ repeat. In the initial stages of aggregation, JD retains a native-like secondary structure, but is deployed of catalytic activity pointing to a subtle conformational change before fibril assembly (Masino et al., 2011). Although the JD plays a central role in this aggregation process, recent studies show that the ataxin-3 flexible region (Masino et al., 2003; Scarff et al., 2012), encompassing UIM1, and UIM2 also contributes to aggregation of the full-length protein (Santambrogio et al., 2012). This multistep aggregation modulated by the polyQ protein context seems to be common in other polyQ disorders such as HD (Thakur et al., 2009) and SCA1 (de Chiara et al., 2005). The presence of an expanded polyQ tract leads subsequently to rapid inter-fibril association and formation of large, highly stable amyloid-like fibrils. This indicates that the non-polyQ domains predispose ataxin-3 for aggregation and that the presence of a pathological polyQ tract introduces an additional step resulting in the formation of a highly stable amyloid-like aggregate.

This complex aggregation mechanism, involving domains outside the amino acid-repeat region, is also found in PABPN1(Tavanez et al., 2005; Winter et al., 2013), a multi-domain polyA-containing protein consisting of an $\mathrm{N}$-terminal segment containing the alanine repeat, a coiled-coil domain, a RNA recognition motif (RRM), and a C-terminal domain. As observed for ataxin-3, the propensity of PABPN1 to aggregate and form amyloid fibrils (Scheuermann et al., 2003) is not exclusive of the expanded protein and can also be observed in the non-disease protein (Tavanez et al., 2005; Rohrberg et al., 2008). This indicates that polyA-flanking regions/domains influence the aggregation process, and that this is likely a broader mechanism common in homopeptide repeat-containing proteins. In fact, analysis of PABPN1 sequence indicates higher scores for aggregation propensity within the RRM domain (Tavanez et al., 2009), with mutations in the RRM being sufficient to prevent aggregate formation (Tavanez et al., 2005).

Aggregation of homopeptide repeat-containing proteins is therefore a multiparametric process that culminates in cell-specific degeneration, whose toxicity might be explained by the contextdependent molecular interactions and post-translational modifications. The relation between protein interactions, function, and aggregation will be discussed below, with a particular focus on the polyQ-containing protein, ataxin-3.

\section{ATAXIN-3 FUNCTION VS. AGGREGATION}

Several studies have been focused on the search for specific ataxin3 interactors, some of which have identified direct physical association between the protein partners and provided clues into ataxin-3 biological role (Table 2 and references herein; Figure 5). Recently, different high throughput interactome screens focused on the search for protein complexes associated with ubiquitin hydrolases 
(Sowa et al., 2009), ataxia-related proteins (Lim et al., 2006), signal transduction pathways (Vinayagam et al., 2011), and transcriptional regulation (Ravasi et al., 2010), contributing with data on novel putative ataxin-3 binding proteins (Table 2; Figures 4 and 5 ).

An overview of the current data on the ataxin-3 interactome shows that a large number of interactions map to the catalytic JD. The intrinsic tendency of JD to self-associate involves the hydrophobic patches on its surface, which overlap with the functionally relevant ubiquitin binding sites 1 and 2 (Matos et al., 2011; Pastore and Temussi, 2012), providing a direct link between protein function and aggregation and exposing a role for intracellular interactors, such as ubiquitin, in protecting against ataxin3 self-assembly (Gales et al., 2005; Masino et al., 2011; Matos et al., 2011; Pastore and Temussi, 2012). Likewise, in the polyAcontaining protein PABPN1 the RRM domain responsible for the interaction with the mRNA (Banerjee et al., 2013) and with polyadenylate-specific RNA polymerase is also involved in the aggregation process (Winter et al., 2013). In addition, the fact that heat-shock proteins including Hsp70, and type I arginine methyl transferases (PRMT1 and PRMT3) associate preferentially with expanded PABPN1 raises the question whereas proteotoxicity of expanded PABPN1 might also be caused by altered protein networking. Destabilization of the ataxin-3 JD by specific mutations revealed that any conformational change in this region is directly linked with aggregation of the full-length protein (Saunders et al., 2011), emphasizing the putative therapeutical potential associated with the identification of macro-molecules with the ability to stabilize this $\mathrm{N}$-terminal region. In fact, interaction of JD with protein partners (Masino et al., 2011) or chaperones (Robertson et al., 2010) is sufficient to induce stabilization of JD leading to a reduction in ataxin-3 self-assembling properties (Matos et al., 2011; Pastore and Temussi, 2012).

Concerning the C-terminal flexible tail of ataxin-3, the interaction with $\mathrm{VCP} / \mathrm{p} 97$ is probably the one for which more experimental data is available (Hirabayashi et al., 2001; Doss-Pepe et al., 2003; Matsumoto et al., 2004; Boeddrich et al., 2006; Zhong and Pittman, 2006). This association is dependent on the arginine/lysine-rich motifs close to the polyQ tract of ataxin-3 (Boeddrich et al., 2006), and several reports point to a stronger interaction with the diseaseprotein containing longer polyQ stretches (Wang et al., 2000; Matsumoto et al., 2004; Boeddrich et al., 2006; Zhong and Pittman, 2006). Functional interaction with $\mathrm{VCP} / \mathrm{p} 97$ is able to modulate the fibrillogenesis of a C-terminal fragment of expanded ataxin-3 (71Q) in a concentration-dependent manner, with equimolar concentrations of $\mathrm{VCP} / \mathrm{p} 97$ stimulating fibrillogenesis, while a fourfold excess of VCP prevented aggregation (Boeddrich et al., 2006). This study provides clues toward the role of interactors targeting the C-terminal region of ataxin-3 as modulators of its oligomerization properties, indicating that this mostly unstructured region (Masino et al., 2003; Scarff et al., 2012) may also represent a bridge between physiological interactions, function, and aggregation. In the field of polyQ disorders, the search for protein interactors is an active area of research, uncovering novel macromolecular partners often acting as disease modifiers (Goehler et al., 2004; Kaltenbach et al., 2007; McGurk and Bonini, 2012). A recent screen for modifiers of ataxin-1 aggregation and toxicity in mammalian cells showed that toxicity enhancers often contained coiled-coil domains. Importantly, coiled-coil formation by ataxin-3 polyQ stretch and its flanking domains were also predicted (Fiumara et al., 2010), however neither the consequences of its expansion nor its functional properties were experimentally assessed. Since coiled-coil structures are known to be involved in protein-protein interactions (Parry et al., 2008; Fiumara et al., 2010), it would be interesting to access the role of protein interactions mediated by the polyQ region of ataxin-3 in regulating its aggregation behavior (Figure 4). In fact, some of the interactors associated with ataxin-3 nuclear functions, rich in polyQ- (p300, NCOR, CBP), and polyA-repeats (NCOR), target this region and are predicted to bind better to the expanded protein (Figures 4 and 5). Therefore it is tempting to speculate that these anomalously stronger interactions with the expanded protein in the nucleus might be associated with increased aggregation and toxicity observed when a strong nuclear localization sequence (NLS) is fused to ataxin3 (Perez et al., 1998; Bichelmeier et al., 2007; Macedo-Ribeiro et al., 2009) or when the protein shuttles to the nucleus upon increased cellular stress (Reina et al., 2010). Heat-shock induces phosphorylation of a serine residue located on ataxin-3 JD and drives the protein to the nucleus leading to its dissociation from the cytosolic VCP/HHR23A complex (Reina et al., 2010), highlighting the dynamic nature of ataxin-3 partition between macromolecular assemblies and making it tempting to speculate that polyQ expansion might affect this distribution.

\section{CONCLUDING REMARIKS}

Trinucleotide repeats are keen for driving evolution by providing genetic variability, with homopeptide-encoded regions being crucial for the establishment of protein interactions. However, as unstable regions, expansion of the homopeptide regions might occur, being responsible for several neurodegenerative and muscular diseases. Homopeptide repeats such as polyQ and polyA seem to influence and to drive the repeat-containing protein toward selfassembly and aggregation. On the other hand, structural studies were able to reveal that aggregation of homopeptide-containing proteins also depends on the homopeptide protein context with additional protein domains playing a role in a multi-domain selfassembly mechanism. Differential expression of protein isoforms generated by alternative splicing, post-translational modifications and, additionally, differences in macromolecular interactions are currently advanced as hypotheses that, by their ability to modulate protein function and aggregation, could explain the cell-specific toxicity of the homopeptide-expanded proteins.

Ataxin-3 is an excellent example of a repeat-containing protein that, upon polyQ-expansion, does not undergo drastic structural and functional changes, but achieves an increased tendency toward self-assembly and aggregation. The protein has deubiquitinase activity and plays a role in the cell-quality control system, and in transcriptional regulation. As a result of its modular multi-domain structure, ataxin-3 engages in multiple macromolecular interactions and several evidences show that it associates with several functional multiprotein complexes, in some cases in a polyQ-dependent manner. The structural and mechanistic details regulating ataxin-3 redistribution between different cellular machineries are still unclear, although posttranslational modifications of the protein subunits assembled in 
these complexes are likely to play a role. Different cellular events such as proteotoxic stress or aging might unbalance the association of expanded ataxin-3 with its molecular partners and contribute to the alteration of ataxin-3 normal cellular functions. Since ataxin-3 self-assembly is a complex process that involves several protein domains, including JD, the relocalization of the protein to different complexes might induce the exposure of aggregationprone regions and lead to the appearance of the characteristic intracellular protein inclusions.

Since macromolecular interactions seem to be either protective or exacerbate aggregation of the homopeptide-containing proteins, they might be targeted therapeutically. However, an indepth understanding about the effect of homopeptide-expansion in the function of the containing-protein and on the interactions with molecular partners is required, in order to understand how they contribute to neurodegeneration. The combination of biochemical and computational approaches to the identification of disease-protein interaction networks is critical for defining their

\section{REFERENCES}

Alba, M. M., and Guigo, R. (2004). Comparative analysis of amino acid repeats in rodents and humans. Genome Res. 14, 549-554. doi:10.1101/gr.1925704

Albrecht, M., Golatta, M., Wullner, U., and Lengauer, T. (2004). Structural and functional analysis of ataxin2 and ataxin-3. Eur. J. Biochem. 271, 3155-3170. doi:10.1111/j.14321033.2004.04245.x

Altschuler, E. L., Hud, N. V., Mazrimas, J. A., and Rupp, B. (1997). Random coil conformation for extended polyglutamine stretches in aqueous soluble monomeric peptides. J. Pept. Res. 50, 73-75. doi:10.1111/j.13993011.1997.tb00622.x

Amiel, J., Trochet, D., Clement-Ziza, M., Munnich, A., and Lyonnet, S. (2004). Polyalanine expansions in human. Hum. Mol. Genet. 2, R235243. doi:10.1093/hmg/ddh251

Antony, P. M., Mantele, S., Mollenkopf, P., Boy, J., Kehlenbach, R. H., Riess, O., et al. (2009). Identification and functional dissection of localization signals within ataxin3. Neurobiol. Dis. 36, 280-292. doi:10.1016/j.nbd.2009.07.020

Arrasate, M., Mitra, S., Schweitzer, E. S., Segal, M. R., and Finkbeiner, S. (2004). Inclusion body formation reduces levels of mutant huntingtin and the risk of neuronal death. Nature 431, 805-810. doi:10.1038/nature02998

Banerjee, A., Apponi, L. H., Pavlath, G. K., and Corbett, A. H. (2013). PABPN1: molecular function and muscle disease. FEBS J. doi:10.1111/febs.12294

Beckwith, A. C., Wall, J. S., and Jordan, R. W. (1965). Reversible reduction and reoxidation of the disulfide bonds in wheat gliadin. Arch. Biochem. Biophys. 112, 16-24. doi:10.1016/0003-9861(65)90004-4

Berke, S. J., Chai, Y., Marrs, G. L., Wen, H., and Paulson, H. L. (2005). Defining the role of ubiquitininteracting motifs in the polyglutamine disease protein, ataxin-3. J. Biol. Chem. 280, 32026-32034. doi:10.1074/jbc.M506084200

Bevivino, A. E., and Loll, P. J. (2001). An expanded glutamine repeat destabilizes native ataxin-3 structure and mediates formation of parallel beta-fibrils. Proc. Natl. Acad. Sci. U.S.A. 98, 11955-11960. doi:10.1073/pnas.211305198

Bhattacharyya, A., Thakur, A. K., Chellgren, V. M., Thiagarajan, G., Williams, A. D., Chellgren, B. W., et al. (2006). Oligoproline effects on polyglutamine conformation and aggregation. J. Mol. Biol. 355, 524-535. doi:10.1016/j.jmb.2005.10.053

Bichelmeier, U., Schmidt, T., Hubener, J., Boy, J., Ruttiger, L., Habig, K., et al. (2007). Nuclear localization of ataxin-3 is required for the manifestation of symptoms in SCA3: in vivo evidence. J. Neurosci. 27, 7418-7428. doi:10.1523/ JNEUROSCI.4540-06.2007

Blum, E. S., Abraham, M. C., Yoshimura, S., Lu, Y., and Shaham, S. (2012). Control of nonapoptotic developmental cell death in Caenorhabditis elegans by a polyglutaminerepeat protein. Science 335, 970-973. doi:10.1126/science.1215156

Blum, E. S., Schwendeman, A. R., and Shaham, S. (2013). PolyQ disease: misfiring of a developmental cell death program? Trends Cell Biol. 23, 168-174. doi:10.1016/j.tcb.2012.11.003

normal function, identifying new markers for disease prognosis and also for the development of tools to selectively target those interactions with potentially reduced side effects.

\section{ACKNOWLEDGMENTS}

We thank Pedro J. B. Pereira and Ana Luísa Carvalho, for critical reading of the manuscript. Research in SM-R lab is funded by FEDER funds through the Operational Competitiveness Programme - Compete and by National Funds through FCT - Fundação para a Ciência e a Tecnologia under the projects FCOMP-010124-FEDER-022718 (PEst-C/SAU/LA0002/2011), FCOMP-010124-FEDER-007075 (PTDC/BIA-PRO/70455/2006), FCOMP01-0124-FEDER-009031 (PTDC/BIA-PRO/100059/2008), and FCOMP-01-0124-FEDER-015860 (PTDC/SAU-NMC/110602/ 2009). Bruno Almeida, Sara Fernandes, and Isabel A. Abreu acknowledge the financial support from FCT through fellowships SFRH/BPD/70783/2010 SFRH/BPD/77009/2011, and Ciência 2008 Programme, respectively.

Boeddrich, A., Gaumer, S., Haacke, A., Tzvetkov, N., Albrecht, M., Evert, B. O., et al. (2006). An arginine/lysine-rich motif is crucial for VCP/p97-mediated modulation of ataxin-3 fibrillogenesis. EMBO J. 25, 1547-1558. doi:10.1038/sj.emboj.7601043

Brais, B. (2003). Oculopharyngeal muscular dystrophy: a late-onset polyalanine disease. Cytogenet. Genome Res. 100, 252-260. doi:10.1159/000072861

Brouwer, J. R., Willemsen, R., and Oostra, B. A. (2009). Microsatellite repeat instability and neurological disease. Bioessays 31, 71-83. doi:10.1002/bies.080122

Bulone, D., Masino, L., Thomas, D. J., San Biagio, P. L., and Pastore, A. (2006). The interplay between PolyQ and protein context delays aggregation by forming a reservoir of protofibrils. PLOS ONE 1:e111. doi:10.1371/journal.pone.0000111

Burnett, B., Li, F., and Pittman, R. N. (2003). The polyglutamine neurodegenerative protein ataxin-3 binds polyubiquitylated proteins and has ubiquitin protease activity. Hum. Mol. Genet. 12, 3195-3205. doi:10.1093/hmg/ ddg344

Burnett, B. G., and Pittman, R. N. (2005). The polyglutamine neurodegenerative protein ataxin 3 regulates aggresome formation. Proc. Natl. Acad. Sci. U.S.A. 102, 4330-4335. doi:10.1073/pnas.0407252102

Butland, S. L., Devon, R. S., Huang, Y., Mead, C. L., Meynert, A. M., Neal, S. J., et al. (2007). CAGencoded polyglutamine length polymorphism in the human genome. BMC Genomics 8:126. doi:10.1186/1471-2164-8-126
Ceol, A., Chatr Aryamontri, A., Licata, L., Peluso, D., Briganti, L., Perfetto, L., et al. (2010). MINT, the molecular interaction database: 2009 update. Nucleic Acids Res. 38, D532-539. doi:10.1093/nar/gkp983

Chai, Y., Berke, S. S., Cohen, R. E., and Paulson, H. L. (2004). Poly-ubiquitin binding by the polyglutamine disease protein ataxin-3 links its normal function to protein surveillance pathways. J. Biol. Chem. 279, 3605-3611. doi:10.1074/jbc.M310939200

Chen, S., Berthelier, V., Hamilton, J. B., O'nuallain, B., and Wetzel, R. (2002a). Amyloid-like features of polyglutamine aggregates and their assembly kinetics. Biochemistry 41, 7391-7399. doi:10.1021/bi01 $1772 \mathrm{q}$

Chen, S., Ferrone, F. A., and Wetzel, R. (2002b). Huntington's disease ageof-onset linked to polyglutamine aggregation nucleation. Proc. Natl. Acad. Sci. U.S.A. 99, 11884-11889. doi:10.1073/pnas.182276099

Chen, Y. W., Stott, K., and Perutz, M. F. (1999). Crystal structure of a dimeric chymotrypsin inhibitor 2 mutant containing an inserted glutamine repeat. Proc. Natl. Acad. Sci. U.S.A. 96, 1257-1261. doi:10.1073/pnas.96.4.1257

Chow, M. K., Ellisdon, A. M., Cabrita, L. D., and Bottomley, S. P. (2004a). Polyglutamine expansion in ataxin-3 does not affect protein stability: implications for misfolding and disease. $J$. Biol. Chem. 279, 47643-47651. doi:10.1074/jbc.M405799200

Chow, M. K., Mackay, J. P., Whisstock, J. C., Scanlon, M. J., and Bottomley, S. P. (2004b). Structural and functional analysis of the 
Josephin domain of the polyglutamine protein ataxin-3. Biochem. Biophys. Res. Commun. 322, 387-394. doi:10.1016/j.bbrc.2004.07.131

Chow, M. K., Paulson, H. L., and Bottomley, S. P. (2004c). Destabilization of a non-pathological variant of ataxin-3 results in fibrillogenesis via a partially folded intermediate: a model for misfolding in polyglutamine disease. J. Mol. Biol. 335, 333-341. doi:10.1016/j.jmb.2003.08.064

Chu-Wang, I. W., and Oppenheim, R. W. (1978). Cell death of motoneurons in the chick embryo spinal cord. I. A light and electron microscopic study of naturally occurring and induced cell loss during development. J. Comp. Neurol. 177, 33-57. doi:10.1002/cne. 901770105

Costa, M. C., Gomes-Da-Silva, J., Miranda, C. J., Sequeiros, J., Santos, M. M., and Maciel, P. (2004). Genomic structure, promoter activity, and developmental expression of the mouse homologue of the Machado-Joseph disease (MJD) gene. Genomics 84, 361-373. doi:10.1016/j.ygeno.2004.02.012

Costa Mdo, C., and Paulson, H. L. (2012). Toward understanding Machado-Joseph disease. Prog. Neurobiol. 97, 239-257. doi:10.1016/ j.pneurobio.2011.11.006

Coutinho, P., and Andrade, C. (1978). Autosomal dominant system degeneration in Portuguese families of the Azores Islands. A new genetic disorder involving cerebellar, pyramidal, extrapyramidal and spinal cord motor functions. Neurology 28, 703-709. doi:10.1212/WNL.28.7.703

Coutinho, P., Guimaraes, A., and Scaravilli, F. (1982). The pathology of Machado-Joseph disease. Report of a possible homozygous case. Acta Neuropathol. 58, 48-54. doi:10.1007/BF00692697

Crick, S. L., Jayaraman, M., Frieden, C., Wetzel, R., and Pappu, R. V. (2006). Fluorescence correlation spectroscopy shows that monomeric polyglutamine molecules form collapsed structures in aqueous solutions. Proc. Natl. Acad. Sci. U.S.A. 103, 16764-16769. doi:10.1073/pnas.0608175103

Cushman, M., Johnson, B. S., King, O. D., Gitler, A. D., and Shorter, J. (2010). Prion-like disorders: blurring the divide between transmissibility and infectivity. J. Cell. Sci. 123, 1191-1201. doi:10.1242/jcs.051672

Davies, S. W., Turmaine, M., Cozens, B. A., Difiglia, M., Sharp, A. H., Ross, C. A., et al.
(1997). Formation of neuronal intranuclear inclusions underlies the neurological dysfunction in mice transgenic for the HD mutation. Cell 90, 537-548. doi:10.1016/ S0092-8674(00)80513-9

de Chiara, C., Menon, R. P., Dal Piaz, F., Calder, L., and Pastore, A. (2005). Polyglutamine is not all: the functional role of the AXH domain in the ataxin-1 protein. J. Mol. Biol. 354, 883-893. doi:10.1016/j.jmb.2005.09.083

de Mezer, M., Wojciechowska, M., Napierala, M., Sobczak, K., and Krzyzosiak, W. J. (2011). Mutant CAG repeats of Huntingtin transcript fold into hairpins, form nuclear foci and are targets for RNA interference. Nucleic Acids Res. 39, 3852-3863. doi:10.1093/nar/gkq1323

Doss-Pepe, E. W., Stenroos, E. S., Johnson, W. G., and Madura, K. (2003). Ataxin-3 interactions with $\operatorname{rad} 23$ and valosin-containing protein and its associations with ubiquitin chains and the proteasome are consistent with a role in ubiquitinmediated proteolysis. Mol. Cell. Biol. 23, 6469-6483. doi:10.1128/ MCB.23.18.6469-6483.2003

Dosztanyi, Z., Chen, J., Dunker, A. K., Simon, I., and Tompa, P. (2006). Disorder and sequence repeats in hub proteins and their implications for network evolution. J. Proteome Res. 5, 2985-2995. doi:10.1021/pr060171o

Dougan, L., Li, J., Badilla, C. L., Berne, B. J., and Fernandez, J. M. (2009). Single homopolypeptide chains collapse into mechanically rigid conformations. Proc. Natl. Acad. Sci. U.S.A. 106, 12605-12610. doi:10.1073/pnas.0900678106

Durcan, T. M., and Fon, E. A. (2013). Ataxin-3 and its e3 partners: implications for MachadoJoseph disease. Front Neurol 4:46. doi:10.3389/fneur.2013.00046

Durcan, T. M., Kontogiannea, M., Bedard, N., Wing, S. S., and Fon, E. A. (2012). Ataxin-3 deubiquitination is coupled to Parkin ubiquitination via $\mathrm{E} 2$ ubiquitin-conjugating enzyme. J. Biol. Chem. 287, 531-541. doi:10.1074/jbc.M111.288449

Durcan, T. M., Kontogiannea, M., Thorarinsdottir, T., Fallon, L., Williams, A. J., Djarmati, A., et al. (2011). The Machado-Joseph disease-associated mutant form of ataxin-3 regulates parkin ubiquitination and stability. Hum. Mol. Genet. 20, 141-154. doi:10.1093/hmg/ddq452

Ellisdon, A. M., Pearce, M. C., and Bottomley, S. P. (2007). Mechanisms of ataxin-3 misfolding and fibril formation: kinetic analysis of a disease-associated polyglutamine protein. J. Mol. Biol. 368, 595-605. doi:10.1016/j.jmb.2007.02.058

Ellisdon, A. M., Thomas, B., and Bottomley, S. P. (2006). The two-stage pathway of ataxin3 fibrillogenesis involves a polyglutamine-independent step. J. Biol. Chem. 281, 16888-16896. doi:10.1074/jbc.M601470200

Evert, B. O., Araujo, J., Vieira-Saecker, A. M., De Vos, R. A., Harendza S., Klockgether, T., et al. (2006). Ataxin-3 represses transcription via chromatin binding, interaction with histone deacetylase 3 , and histone deacetylation. J. Neurosci. 26, 11474-11486. doi:10.1523/ JNEUROSCI.2053-06.2006

Faux, N. G., Bottomley, S. P., Lesk, A. M., Irving, J. A., Morrison, J. R., De La Banda, M. G., et al. (2005). Functional insights from the distribution and role of homopeptide repeatcontaining proteins. Genome Res. 15 , 537-551. doi:10.1101/gr.3096505

Fei, E., Jia, N., Zhang, T., Ma, X., Wang, H., Liu, C., et al. (2007). Phosphorylation of ataxin-3 by glycogen synthase kinase 3 beta at serine 256 regulates the aggregation of ataxin-3. Biochem. Biophys. Res. Commun. 357, 487-492. doi:10.1016/j.bbrc.2007.03.160

Ferro, A., Carvalho, A. L., TeixeiraCastro, A., Almeida, C., Tome, R. J., Cortes, L., et al. (2007). NEDD8: a new ataxin-3 interactor. Biochim. Biophys. Acta 1773, 1619-1627. doi:10.1016/j.bbamcr.2007.07.012

Fiumara, F., Fioriti, L., Kandel, E. R., and Hendrickson, W. A. (2010). Essential role of coiled coils for aggregation and activity of $\mathrm{Q} / \mathrm{N}$-rich prions and PolyQ proteins. Cell 143,1121-1135. doi:10.1016/j.cell.2010.11.042

Fondon, J. W. III, and Garner H. R. (2004). Molecular origins of rapid and continuous morphological evolution. Proc. Natl. Acad. Sci. U.S.A. 101, 18058-18063. doi:10.1073/pnas.0408118101

Friedman, M. J., Shah, A. G., Fang, Z. H., Ward, E. G., Warren, S. T., Li, S., et al. (2007). Polyglutamine domain modulates the TBP-TFIIB interaction: implications for its normal function and neurodegeneration. Nat. Neurosci. 10, 1519-1528. doi:10.1038/nn2011

Gales, L., Cortes, L., Almeida, C., Melo, C. V., Costa, M. C., Maciel, P., et al. (2005). Towards a structural understanding of the fibrillization pathway in MachadoJoseph's disease: trapping early oligomers of non-expanded ataxin-3. J. Mol. Biol. 353, 642-654. doi:10.1016/j.jmb.2005.08.061

Gerber, H. P., Seipel, K., Georgiev, O., Hofferer, M., Hug, M., Rusconi, S., et al. (1994). Transcriptional activation modulated by homopolymeric glutamine and proline stretches. Science 263, 808-811. doi:10.1126/science.8303297

Goehler, H., Lalowski, M., Stelzl, U., Waelter, S., Stroedicke, M., Worm, U., et al. (2004). A protein interaction network links GIT1, an enhancer of huntingtin aggregation, to Huntington's disease. Mol. Cell 15, 853-865. doi:10.1016/j.molcel.2004.09.016

Gojobori, J., and Ueda, S. (2011). Elevated evolutionary rate in genes with homopolymeric amino acid repeats constituting nondisordered structure. Mol. Biol. Evol. 28, 543-550. doi:10.1093/molbev/msq225

Gonitel, R., Moffitt, H., Sathasivam, K., Woodman, B., Detloff, P. J., Faull, R. L., et al. (2008). DNA instability in postmitotic neurons. Proc. Natl. Acad. Sci. U.S.A. 105, 3467-3472. doi:10.1073/pnas.0800048105

Goto, J., Watanabe, M., Ichikawa, Y., Yee, S. B., Ihara, N., Endo, K., et al. (1997). Machado-Joseph disease gene products carrying different carboxyl termini. Neurosci. Res. 28, 373-377. doi:10.1016/S01680102(97)00056-4

Guo, L., Han, A., Bates, D. L., Cao, J., and Chen, L. (2007). Crystal structure of a conserved $\mathrm{N}$ terminal domain of histone deacetylase 4 reveals functional insights into glutamine-rich domains. Proc. Natl. Acad. Sci. U.S.A. 104, 4297-4302. doi:10.1073/pnas.0608041104

Haerty, W., and Golding, G. B. (2010). Low-complexity sequences and single amino acid repeats: not just "junk" peptide sequences. Genome 53, 753-762. doi:10.1139/g10-063

Hammock, E. A., and Young, L. J. (2005). Microsatellite instability generates diversity in brain and sociobehavioral traits. Science 308, 1630-1634. doi:10.1126/science.1111427

Hancock, J. M., and Simon, M. (2005). Simple sequence repeats in proteins and their significance for network evolution. Gene 345, 113-118. doi:10.1016/j.gene.2004. 11.023

Harris, G. M., Dodelzon, K., Gong, L., Gonzalez-Alegre, P., and Paulson, H. L. (2010). Splice isoforms of the polyglutamine disease protein ataxin- 3 exhibit similar enzymatic yet different aggregation 
properties. PLoS ONE 5:e13695. doi:10.1371/journal.pone.0013695

Heir, R., Ablasou, C., Dumontier, E., Elliott, M., Fagotto-Kaufmann, C., and Bedford, F. K. (2006). The UBL domain of PLIC-1 regulates aggresome formation. EMBO Rep. 7, 1252-1258. doi:10.1038/sj.embor.7400823

Hirabayashi, M., Inoue, K., Tanaka, K., Nakadate, K., Ohsawa, Y., Kamei, Y., et al. (2001). VCP/p97 in abnormal protein aggregates, cytoplasmic vacuoles, and cell death, phenotypes relevant to neurodegeneration. Cell Death Differ. 8, 977-984. doi:10.1038/sj.cdd.4400907

Huang, C. C., Faber, P. W., Persichetti, F., Mittal, V., Vonsattel, J. P., Macdonald, M. E., et al. (1998). Amyloid formation by mutant huntingtin: threshold, progressivity and recruitment of normal polyglutamine proteins. Somat. Cell Mol. Genet. 24, 217-233. doi:10.1023/ B:SCAM.0000007124.19463.e5

Huntley, M. A., and Golding, G. B. (2002). Simple sequences are rare in the Protein Data Bank. Proteins 48, 134-140. doi:10.1002/prot.10150

Jana, N. R., Dikshit, P., Goswami, A., Kotliarova, S., Murata, S., Tanaka, K., et al. (2005). Co-chaperone CHIP associates with expanded polyglutamine protein and promotes their degradation by proteasomes. J. Biol. Chem. 280, 11635-11640. doi:10.1074/jbc.M412042200

Jayaraman, M., Thakur, A. K., Kar, K., Kodali, R., and Wetzel, R. (2011). Assays for studying nucleated aggregation of polyglutamine proteins. Methods 53, 246-254. doi:10.1016/j.ymeth.2011.01.001

Kaltenbach, L. S., Romero, E., Becklin, R. R., Chettier, R., Bell, R., Phansalkar, A., et al. (2007). Huntingtin interacting proteins are genetic modifiers of neurodegeneration. PLoS Genet. 3:e82. doi:10.1371/journal.pgen.0030082

Kar, K., Jayaraman, M., Sahoo, B., Kodali, R., and Wetzel, R. (2011). Critical nucleus size for diseaserelated polyglutamine aggregation is repeat-length dependent. Nat. Struct. Mol. Biol. 18, 328-336. doi:10.1038/nsmb.1992

Kashi, Y., King, D., and Soller, M. (1997). Simple sequence repeats as a source of quantitative genetic variation. Trends Genet. 13, 74-78. doi:10. 1016/S0168-9525(97)01008-1

Kashi, Y., and King, D. G. (2006). Simple sequence repeats as advantageous mutators in evolution. Trends Genet. 22, 253-259. doi:10.1016/j.tig.2006.03.005
Kawaguchi, Y., Okamoto, T., Taniwaki, M., Aizawa, M., Inoue, M., Katayama, S., et al. (1994). CAG expansions in a novel gene for Machado-Joseph disease at chromosome 14q32.1. Nat. Genet. 8, 221-228. doi:10.1038/ng1194-221

Kayed, R., Head, E., Thompson, J. L., Mcintire, T. M., Milton, S. C., Cotman, C. W., et al. (2003). Common structure of soluble amyloid oligomers implies common mechanism of pathogenesis. Science 300, 486-489. doi:10.1126/science. 1079469

Kiliszek, A., Kierzek, R., Krzyzosiak, W. J., and Rypniewski, W. (2010). Atomic resolution structure of CAG RNA repeats: structural insights and implications for the trinucleotide repeat expansion diseases. Nucleic Acids Res. 38, 8370-8376. doi:10.1093/nar/gkq700

Kiliszek, A., Kierzek, R., Krzyzosiak, W. J., and Rypniewski, W. (2011). Crystal structures of CGG RNA repeats with implications for fragile $\mathrm{X}$ associated tremor ataxia syndrome. Nucleic Acids Res. 39, 7308-7315. doi:10.1093/nar/gkr368

Kim, M. W., Chelliah, Y., Kim, S. W., Otwinowski, Z., and Bezprozvanny, I. (2009). Secondary structure of Huntingtin amino-terminal region. Structure 17, 1205-1212. doi:10.1016/j.str.2009.08.002

King, D. G. (1994). Triple repeat DNA as a highly mutable regulatory mechanism. Science 263, 595-596. doi:10.1126/science.263.5147.595-b

Klein, F. A., Pastore, A., Masino, L., Zeder-Lutz, G., Nierengarten, H., Oulad-Abdelghani, M., et al. (2007). Pathogenic and nonpathogenic polyglutamine tracts have similar structural properties: towards a length-dependent toxicity gradient. J. Mol. Biol. 371, 235-244. doi:10.1016/j.jmb.2007. 05.028

Korschen, H. G., Beyermann, M., Muller, F., Heck, M., Vantler, M., Koch, K. W., et al. (1999). Interaction of glutamic-acid-rich proteins with the cGMP signalling pathway in rod photoreceptors. Nature 400, 761-766. doi:10.1038/23468

Kratter, I. H., and Finkbeiner, S. (2010). PolyQ disease: too many Qs, too much function? Neuron 67, 897-899. doi:10.1016/j.neuron.2010.09.012

Krull, L. H., Wall, J. S., Zobel, H., and Dimler, R. J. (1965). Synthetic polypeptides containing sidechain amide groups: water-insoluble polymers. Biochemistry 4, 626-633. doi:10.1021/bi00880a003
Krzyzosiak, W. J., Sobczak, K., Wojciechowska, M., Fiszer, A., Mykowska, A., and Kozlowski, P. (2012). Triplet repeat RNA structure and its role as pathogenic agent and therapeutic target. Nucleic Acids Res. 40, 11-26. doi:10.1093/nar/gkr729

Kumar, A., Park, H., Fang, P., Parkesh, R., Guo, M., Nettles, K. W., et al. (2011). Myotonic dystrophy type 1 RNA crystal structures reveal heterogeneous $1 \times 1$ nucleotide UU internal loop conformations. Biochemistry 50, 9928-9935. doi:10.1021/bi2013068

La Spada, A. R. (1997). Trinucleotide repeat instability: genetic features and molecular mechanisms. Brain Pathol. 7, 943-963. doi:10.1111/j.17503639.1997.tb00895.x

La Spada, A. R., Paulson, H. L., and Fischbeck, K. H. (1994). Trinucleotide repeat expansion in neurological disease. Ann. Neurol. 36, 814-822. doi:10.1002/ana.410360604

La Spada, A. R., Wilson, E. M. Lubahn, D. B., Harding, A. E., and Fischbeck, K. H. (1991). Androgen receptor gene mutations in $\mathrm{X}$-linked spinal and bulbar muscular atrophy. Nature 352, 77-79. doi:10.1038/352077a0

Laganowsky, A., Liu, C., Sawaya, M. R., Whitelegge, J. P., Park, J., Zhao, M., et al. (2012). Atomic view of a toxic amyloid small oligomer. Science 335, 1228-1231. doi:10.1126/science. 1213151

Li, F., Macfarlan, T., Pittman, R. N., and Chakravarti, D. (2002). Ataxin-3 is a histone-binding protein with two independent transcriptional corepressor activities. J. Biol. Chem. 277, 45004-45012. doi:10.1074/jbc.M205259200

Li, L. B., and Bonini, N. M. (2010). Roles of trinucleotide-repeat RNA in neurological disease and degeneration. Trends Neurosci. 33, 292-298. doi:10.1016/j.tins.2010.03.004

Li, P., Huey-Tubman, K. E., Gao, T., Li, X., West, A. P. Jr., Bennett, M. J., et al. (2007a). The structure of a polyQanti-polyQ complex reveals binding according to a linear lattice model. Nat. Struct. Mol. Biol. 14, 381-387. doi:10.1038/nsmb1234

Li, X. J., Friedman, M., and Li, S. (2007b). Interacting proteins as genetic modifiers of Huntington disease. Trends Genet. 23, 531-533. doi:10.1016/j.tig.2007.07.007

Liebman, S. W., and Meredith, S. C. (2010). Protein folding: sticky N17 speeds huntingtin pile-up. Nat. Chem. Biol. 6, 7-8. doi:10.1038/nchembio. 279
Lim, J., Crespo-Barreto, J., Jafar-Nejad, P., Bowman, A. B., Richman, R., Hill, D. E., et al. (2008). Opposing effects of polyglutamine expansion on native protein complexes contribute to SCA1. Nature 452, 713-718. doi:10.1038/nature06731

Lim, J., Hao, T., Shaw, C., Patel, A. J., Szabo, G., Rual, J. F., et al. (2006). A protein-protein interaction network for human inherited ataxias and disorders of Purkinje cell degeneration. Cell 125, 801-814. doi:10.1016/j.cell.2006.03.032

Liu, Y., Gotte, G., Libonati, M., and Eisenberg, D. (2001). A domainswapped RNase A dimer with implications for amyloid formation. Nat. Struct. Biol. 8, 211-214. doi:10.1038/84941

Lopez Castel, A., Cleary, J. D., and Pearson, C. E. (2010). Repeat instability as the basis for human diseases and as a potential target for therapy. Nat. Rev. Mol. Cell Biol. 11, 165-170. doi:10.1038/nrm 2854

Macedo-Ribeiro, S., Cortes, L., Maciel, P., and Carvalho, A. L. (2009). Nucleocytoplasmic shuttling activity of ataxin-3. PLoS ONE 4:e5834. doi:10.1371/journal.pone.0005834

Mao, Y., Senic-Matuglia, F., Di Fiore, P. P., Polo, S., Hodsdon, M. E., and De Camilli, P. (2005). Deubiquitinating function of ataxin-3: insights from the solution structure of the Josephin domain Proc. Natl. Acad. Sci. U.S.A. 102, 12700-12705. doi:10.1073/pnas.050 6344102

Marchal, S., Shehi, E., Harricane, M. C., Fusi, P., Heitz, F., Tortora, P., et al. (2003). Structural instability and fibrillar aggregation of non-expanded human ataxin-3 revealed under high pressure and temperature. J. Biol. Chem. 278, 31554-31563. doi:10.1074/jbc.M304205200

Margolis, R. L., and Ross, C. A. (2001). Expansion explosion: new clues to the pathogenesis of repeat expansion neurodegenerative diseases. Trends. Mol. Med. 7, 479-482. doi:10 1016/S1471-4914(01)02179-7

Masino, L., Kelly, G., Leonard, K. Trottier, Y., and Pastore, A. (2002). Solution structure of polyglutamine tracts in GSTpolyglutamine fusion proteins. FEBS Lett. 513, 267-272. doi:10. 1016/S0014-5793(02)02335-9

Masino, L., Musi, V., Menon, R. P., Fusi, P., Kelly, G., Frenkiel, T. A., et al. (2003). Domain architecture of the polyglutamine protein ataxin-3: a globular domain followed by a flexible tail. FEBS 
Lett. 549, 21-25. doi:10.1016/S00145793(03)00748-8

Masino, L., Nicastro, G., Calder, L., Vendruscolo, M., and Pastore, A. (2011). Functional interactions as a survival strategy against abnormal aggregation. FASEB J. 25, 45-54. doi:10.1096/fj.10-161208

Masino, L., Nicastro, G., Menon, R. P., Dal Piaz, F., Calder, L., and Pastore, A. (2004). Characterization of the structure and the amyloidogenic properties of the Josephin domain of the polyglutaminecontaining protein ataxin-3. J. Mol. Biol. 344, 1021-1035. doi:10.1016/j.jmb.2004.09.065

Matos, C. A., De Macedo-Ribeiro, S., and Carvalho, A. L. (2011). Polyglutamine diseases: the special case of ataxin-3 and MachadoJoseph disease. Prog. Neurobiol. 95, 26-48. doi:10.1016/j.pneurobio. 2011.06.007

Matsumoto, M., Yada, M., Hatakeyama, S., Ishimoto, H., Tanimura, T., Tsuji, S., et al. (2004). Molecular clearance of ataxin-3 is regulated by a mammalian E4. EMBO J. 23, 659-669. doi:10.1038/sj.emboj.7600081

Mazzucchelli, S., De Palma, A., Riva, M., D’urzo, A., Pozzi, C., Pastori, V., et al. (2009). Proteomic and biochemical analyses unveil tight interaction of ataxin-3 with tubulin. Int. J. Biochem. Cell Biol. 41, 2485-2492. doi:10.1016/j.biocel.2009.08.003

McGurk, L., and Bonini, N. M. (2012). Protein interacting with C kinase (PICK1) is a suppressor of spinocerebellar ataxia 3-associated neurodegeneration in Drosophila. Hum. Mol. Genet. 21, 76-84. doi:10.1093/hmg/ddr439

Merienne, K., and Trottier, Y. (2009). SCA8 CAG/CTG expansions, a tale of two TOXICities: a unique or common case? PLoS Genet. 5:e1000593. doi:10.1371/journal.pgen.1000593

Messaed, C., Dion, P. A., Abu-Baker, A., Rochefort, D., Laganiere, J., Brais, B., et al. (2007). Soluble expanded PABPN1 promotes cell death in oculopharyngeal muscular dystrophy. Neurobiol. Dis. 26, 546-557. doi:10.1016/j.nbd.2007.02.004

Messaed, C., and Rouleau, G. A. (2009). Molecular mechanisms underlying polyalanine diseases. Neurobiol. Dis. 34, 397-405. doi:10.1016/j.nbd.2009.02.013

Miller, J., Arrasate, M., Brooks, E., Libeu, C. P., Legleiter, J., Hatters, D., et al. (2011). Identifying polyglutamine protein species in situ that best predict neurodegeneration. Nat. Chem. Biol. 7, 925-934. doi:10.1038/nchembio.694
Miller, J., Arrasate, M., Shaby, B. A., Mitra, S., Masliah, E., and Finkbeiner, S. (2010). Quantitative relationships between huntingtin levels, polyglutamine length, inclusion body formation, and neuronal death provide novel insight into huntington's disease molecular pathogenesis. J. Neurosci. 30, 10541-10550. doi:10.1523/ JNEUROSCI.0146-10.2010

Miller, J. W., Urbinati, C. R., TengUmnuay, P., Stenberg, M. G., Byrne, B. J., Thornton, C. A., et al. (2000). Recruitment of human muscleblind proteins to (CUG)(n) expansions associated with myotonic dystrophy. ЕMBO J. 19, 4439-4448. doi:10.1093/emboj/19.17.4439

Miller, V. M., Nelson, R. F., Gouvion, C. M., Williams, A., Rodriguez-Lebron, E., Harper, S. Q., et al. (2005). CHIP suppresses polyglutamine aggregation and toxicity in vitro and in vivo. J. Neurosci. 25, 9152-9161. doi:10.1523/JNEUROSCI.300105.2005

Mooers, B. H., Logue, J. S., and Berglund, J. A. (2005). The structural basis of myotonic dystrophy from the crystal structure of CUG repeats. Proc. Natl. Acad. Sci. U.S.A. 102, 16626-16631. doi:10.1073/pnas.0505873102

Mosca, R., Ceol, A., and Aloy, P. (2012). Interactome3D: adding structural details to protein networks. Nat. Methods 10, 47-53. doi:10.1038/nmeth.2289

Mueller, T., Breuer, P., Schmitt, I., Walter, J., Evert, B. O., and Wullner, U. (2009). CK2-dependent phosphorylation determines cellular localization and stability of ataxin-3. Hum. Mol. Genet. 18, 3334-3343. doi:10.1093/hmg/ddp274

Nagai, Y., Inui, T., Popiel, H. A., Fujikake, N., Hasegawa, K., Urade, Y., et al. (2007). A toxic monomeric conformer of the polyglutamine protein. Nat. Struct. Mol. Biol. 14 332-340. doi:10.1038/nsmb1215

Napierala, M., and Krzyzosiak, W. J. (1997). CUG repeats present in myotonin kinase RNA form metastable "slippery" hairpins. J. Biol. Chem. 272, 31079-31085. doi:10.1074/jbc.272.49.31079

Nicastro, G., Masino, L., Esposito, V., Menon, R. P., De Simone, A., Fraternali, F., et al. (2009). Josephin domain of ataxin-3 contains two distinct ubiquitin-binding sites. Biopolymers 91, 1203-1214. doi:10.1002/bip.21210

Nicastro, G., Menon, R. P., Masino, L., Knowles, P. P., Mcdonald, N. Q., and Pastore, A. (2005). The solution structure of the Josephin domain of ataxin-3: structural determinants for molecular recognition. Proc. Natl. Acad. Sci. U.S.A. 102, 10493-10498. doi:10.1073/pnas.0501732102

Nicastro, G., Todi, S. V., Karaca, E., Bonvin, A. M., Paulson, H. L., and Pastore, A. (2010). Understanding the role of the Josephin domain in the PolyUb binding and cleavage properties of ataxin-3. PLoS ONE 5:e12430 doi:10.1371/journal.pone. 0012430

Nithianantharajah, J., and Hannan, A. J. (2007). Dynamic mutations as digital genetic modulators of brain development, function and dysfunction. Bioessays 29, 525-535. doi:10.1002/bies.20589

Nucifora, F. C. Jr., Sasaki, M., Peters, M. F., Huang, H., Cooper, J. K., Yamada, M., et al. (2001). Interference by huntingtin and atrophin-1 with cbp-mediated transcription leading to cellular toxicity. Science 291, 2423-2428. doi:10.1126/science.1056784

Oma, Y., Kino, Y., Sasagawa, N., and Ishiura, S. (2005). Comparative analysis of the cytotoxicity of homopolymeric amino acids. Biochim. Biophys. Acta 1748, 174-179. doi:10.1016/j.bbapap.2004.12.017

Oma, Y., Kino, Y., Toriumi, K., Sasagawa, N., and Ishiura, S. (2007). Interactions between homopolymeric amino acids (HPAAs). Protein Sci. 16, 2195-2204. doi:10.1110/ps.072955307

Ordway, J. M., Tallaksengreene, S., Gutekunst, C. A., Bernstein, E. M., Cearley, J. A., Wiener, H. W., et al. (1997). Ectopically expressed CAG repeats cause intranuclear inclusions and a progressive late onset neurological phenotype in the mouse. Cell 91, 753-763. doi:10.1016/S00928674(00)80464-X

Orr, H. T. (2012a). Cell biology of spinocerebellar ataxia. J. Cell Biol. 197, 167-177. doi:10.1083/jcb.201105092

Orr, H. T. (2012b). Polyglutamine neurodegeneration: expanded glutamines enhance native functions. Curr. Opin. Genet. Dev. 22, 251-255. doi:10.1016/j.gde.2012.01.001

Orr, H. T., and Zoghbi, H. Y. (2007). Trinucleotide repeat disorders. Annu. Rev. Neurosci. 30, 575-621. doi:10.1146/annurev.neuro. 29. 051605.113042

Parkesh, R., Fountain, M., and Disney, M. D. (2011). NMR spectroscopy and molecular dynamics simulation of r(CCGCUGCGG) reveal a dynamic UU internal loop found in myotonic dystrophy type 1. Biochemistry 50, 599-601. doi:10.1021/bi101896j

Parry, D. A., Fraser, R. D., and Squire, J. M. (2008). Fifty years of coiled-coils and alpha-helical bundles: a close relationship between sequence and structure. J. Struct. Biol. 163, 258-269. doi:10.1016/j.jsb.2008.01.016

Pastore, A., and Temussi, P. A. (2012). The two faces of Janus: functional interactions and protein aggregation. Curr. Opin. Struct. Biol. 22, 30-37. doi:10.1016/j.sbi.2011.11.007

Paulson, H. L., Perez, M. K., Trottier, Y., Trojanowski, J. Q., Subramony, S. H., Das, S. S., et al. (1997). Intranuclear inclusions of expanded polyglutamine protein in spinocerebellar ataxia type 3 . Neuron 19, 333-344. doi:10.1016/S08966273(00)80943-5

Pearson, C. E. (2011). Repeat associated non-ATG translation initiation: one DNA, two transcripts seven reading frames, potentially nine toxic entities! PLoS Genet. 7:e1002018. doi:10.1371/ journal.pgen.1002018

Pearson, C. E., Nichol Edamura, K., and Cleary, J. D. (2005). Repeat instability: mechanisms of dynamic mutations. Nat. Rev. Genet. 6, 729-742. doi:10.1038/nrg1689

Perez, M. K., Paulson, H. L., Pendse, S. J., Saionz, S. J., Bonini, N. M., and Pittman, R. N. (1998). Recruitment and the role of nuclear localization in polyglutamine-mediated aggregation. J. Cell Biol. 143, 1457-1470. doi:10.1083/jcb.143.6.1457

Perez, M. K., Paulson, H. L., and Pittman, R. N. (1999). Ataxin3 with an altered conformation that exposes the polyglutamine domain is associated with the nuclear matrix. Hum. Mol. Genet. 8 , 2377-2385. doi:10.1093/hmg/8.13. 2377

Perutz, M. (1994). Polar zippers: their role in human disease. Protein Sci. 3, 1629-1637. doi:10.1002/pro.5560031002

Peters-Libeu, C., Miller, J., Rutenber, E., Newhouse, Y., Krishnan, P., Cheung, K., et al. (2012). Disease-associated polyglutamine stretches in monomeric huntingtin adopt a compact structure. J. Mol. Biol. 421, 587-600. doi:10.1016/j.jmb.2012.01.034

Petrakis, S., Rasko, T., Russ, J., Friedrich, R. P., Stroedicke, M., Riechers, S. P., et al. (2012). Identification of human proteins that modify misfolding and proteotoxicity of pathogenic 
ataxin-1. PLoS Genet. 8:e1002897. doi:10.1371/journal.pgen.1002897

Pilar, G., and Landmesser, L. (1976). Ultrastructural differences during embryonic cell death in normal and peripherally deprived ciliary ganglia. J. Cell Biol. 68, 339-356. doi:10.1083/jcb.68.2.339

Ravasi, T., Suzuki, H., Cannistraci, C. V., Katayama, S., Bajic, V. B., Tan, K., et al. (2010). An atlas of combinatorial transcriptional regulation in mouse and man. Cell 140, 744-752. doi:10.1016/j.cell.2010.01.044

Reina, C. P., Zhong, X., and Pittman, R. N. (2010). Proteotoxic stress increases nuclear localization of ataxin-3. Hum. Mol. Genet. 19, 235-249. doi:10.1093/hmg/ddp482

Ren, P. H., Lauckner, J. E., Kachirskaia, I., Heuser, J. E., Melki, R., and Kopito, R. R. (2009). Cytoplasmic penetration and persistent infection of mammalian cells by polyglutamine aggregates. Nat. Cell Biol. 11, 219-225. doi:10.1038/ncb 1830

Robertson, A. L., Bate, M. A., Androulakis, S. G., Bottomley, S. P., and Buckle, A. M. (2011). PolyQ: a database describing the sequence and domain context of polyglutamine repeats in proteins. Nucleic Acids Res. 39, D272-D276. doi:10.1093/nar/gkq1100

Robertson, A. L., Headey, S. J., Saunders, H. M., Ecroyd, H., Scanlon, M. J., Carver, J. A., et al. (2010). Small heat-shock proteins interact with a flanking domain to suppress polyglutamine aggregation. Proc. Natl. Acad. Sci. U.S.A. 107, 10424-10429. doi:10.1073/pnas.0914773107

Robertson, A. L., Horne, J., Ellisdon, A. M., Thomas, B., Scanlon, M. J., and Bottomley, S. P. (2008). The structural impact of a polyglutamine tract is location-dependent. Biophys. J. 95, 5922-5930. doi:10.1529/biophysj.108.138487

Rodrigues, A. J., Coppola, G., Santos, C., Costa Mdo, C., Ailion, M., Sequeiros, J., et al. (2007). Functional genomics and biochemical characterization of the C. elegans orthologue of the Machado-Joseph disease protein ataxin-3. FASEB J. 21, 1126-1136. doi:10.1096/fj.06-7002com

Rohrberg, J., Sachs, R., Lodderstedt, G., Sackewitz, M., Balbach, J., and Schwarz, E. (2008). Monitoring fibril formation of the Nterminal domain of PABPN1 carrying an alanine repeat by tryptophan fluorescence and real-time NMR. FEBS Lett. 582, 1587-1592. doi:10.1016/j.febslet.2008.04.002

Rosenberg, R. N. (1992). MachadoJoseph disease: an autosomal dominant motor system degeneration. Mov. Disord. 7, 193-203. doi:10.1002/mds.870070302

Rub, U., De Vos, R. A., Brunt, E. R., Sebesteny, T., Schols, L., Auburger, G., et al. (2006). Spinocerebellar ataxia type 3 (SCA3): thalamic neurodegeneration occurs independently from thalamic ataxin-3 immunopositive neuronal intranuclear inclusions. Brain Pathol. 16, 218-227. doi:10.1111/j.17503639.2006.00022.x

Sambashivan, S., Liu, Y., Sawaya, M. R., Gingery, M., and Eisenberg, D. (2005). Amyloid-like fibrils of ribonuclease A with threedimensional domain-swapped and native-like structure. Nature 437, 266-269. doi:10.1038/nature03916

Santambrogio, C., Frana, A. M., Natalello, A., Papaleo, E., Regonesi, M. E., Doglia, S. M., et al. (2012). The role of the central flexible region on the aggregation and conformational properties of human ataxin-3. FEBS J. 279, 451-463. doi:10.1111/j.17424658.2011.08438.x

Sathasivam, K., Lane, A., Legleiter, J., Warley, A., Woodman, B., Finkbeiner, S., et al. (2010). Identical oligomeric and fibrillar structures captured from the brains of R6/2 and knock-in mouse models of Huntington's disease. Hum. Mol. Genet. 19, 65-78. doi:10.1093/hmg/ddp467

Saunders, H. M., and Bottomley, S. P. (2009). Multi-domain misfolding: understanding the aggregation pathway of polyglutamine proteins. Protein Eng. Des. Sel. 22, 447-451. doi:10.1093/protein/gzp033

Saunders, H. M., Gilis, D., Rooman, M., Dehouck, Y., Robertson, A. L., and Bottomley, S. P. (2011). Flanking domain stability modulates the aggregation kinetics of a polyglutamine disease protein. Protein Sci. 20, 1675-1681. doi:10.1002/pro.698

Scaglione, K. M., Zavodszky, E., Todi, S. V., Patury, S., Xu, P., Rodriguez-Lebron, E., et al. (2011). Ube $2 \mathrm{w}$ and ataxin-3 coordinately regulate the ubiquitin ligase CHIP. Mol. Cell 43, 599-612. doi:10.1016/j.molcel.2011.05.036

Scarff, C. A., Sicorello, A., Tomé, R. J. L., Ashcroft, A. E., Radford, S. E., and Macedo-Ribeiro, S. (2012). A tale of a tail: structural insights into the conformational properties of the polyglutamine protein ataxin-3. Int. J. Mass Spectrom. doi:10.1016/j.ijms.2012.08.032

Schaefer, M. H., Wanker, E. E., and Andrade-Navarro, M. A. (2012). Evolution and function of CAG/polyglutamine repeats in protein-protein interaction networks. Nucleic Acids Res. 40, 4273-4287. doi:10.1093/nar/gks011

Scheel, H., Tomiuk, S., and Hofmann, K. (2003). Elucidation of ataxin-3 and ataxin-7 function by integrative bioinformatics. Hum. Mol. Genet. 12, 2845-2852. doi:10.1093/hmg/ddg297

Scheuermann, T., Schulz, B., Blume, A., Wahle, E., Rudolph, R., and Schwarz, E. (2003). Trinucleotide expansions leading to an extended poly-L-alanine segment in the poly (A) binding protein PABPN1 cause fibril formation. Protein Sci. 12, 2685-2692. doi:10.1110/ps.03214703

Schmitt, I., Linden, M., Khazneh, H. Evert, B. O., Breuer, P., Klockgether, T., et al. (2007). Inactivation of the mouse Atxn3 (ataxin-3) gene increases protein ubiquitination. Biochem. Biophys Res. Commun. 362, 734-739. doi:10.1016/j.bbrc.2007.08.062

Seki, T., Gong, L., Williams, A. J., Sakai, N., Todi, S. V., and Paulson, H. L. (2013). JosD1, a membrane-targeted deubiquitinating enzyme, is activated by ubiquitination and regulates membrane dynamics, cell motility and endocytosis. J. Biol. Chem. doi:10.1074/jbc.M113.463406

Shimohata, T., Nakajima, T., Yamada, M., Uchida, C., Onodera, O., Naruse, S., et al. (2000). Expanded polyglutamine stretches interact with TAFII130, interfering with CREBdependent transcription. Nat. Genet. 26, 29-36. doi:10.1038/79139

Sicot, G., Gourdon, G., and GomesPereira, M. (2011). Myotonic dystrophy, when simple repeats reveal complex pathogenic entities: new findings and future challenges. Hum. Mol. Genet. 20, R116-123. doi:10.1093/hmg/ddr343

Simon, M., and Hancock, J. M. (2009). Tandem and cryptic amino acid repeats accumulate in disordered regions of proteins. Genome Biol. 10 , R59. doi:10.1186/gb-2009-10-6-r59

Singh, V. R., and Lapidus, L. J. (2008). The intrinsic stiffness of polyglutamine peptides. J. Phys. Chem. B 112, 13172-13176. doi:10.1021/jp805636p

Song, A. X., Zhou, C. J., Peng, Y., Gao, X. C., Zhou, Z. R., Fu, Q. S., et al. (2010). Structural transformation of the tandem ubiquitin-interacting motifs in ataxin-3 and their cooperative interactions with ubiquitin chains. PLOS ONE 5:e13202. doi:10.1371/journal.pone.0013202
Sowa, M. E., Bennett, E. J., Gygi, S. P., and Harper, J. W. (2009). Defining the human deubiquitinating enzyme interaction landscape. Cell 138, 389-403. doi:10.1016/j.cell.2009.04.042

Stott, K., Blackburn, J. M., Butler, P. J., and Perutz, M. (1995). Incorporation of glutamine repeats makes protein oligomerize: implications for neurodegenerative diseases. Proc. Natl. Acad. Sci. U.S.A. 92, 6509-6513. doi:10.1073/pnas.92.14.6509

Sugaya, N., and Furuya, T. (2011). Dr. PIAS: an integrative system for assessing the druggability of proteinprotein interactions. BMC Bioinformatics 12:50. doi:10.1186/14712105-12-50

Takahashi, T., Kikuchi, S., Katada, S., Nagai, Y., Nishizawa, M., and Onodera, O. (2008). Soluble polyglutamine oligomers formed prior to inclusion body formation are cytotoxic. Hum. Mol. Genet. 17, 345-356. doi:10.1093/hmg/ddm311

Tam, S., Spiess, C., Auyeung, W., Joachimiak, L., Chen, B., Poirier, M. A., et al. (2009). The chaperonin TRiC blocks a huntingtin sequence element that promotes the conformational switch to aggregation. Nat. Struct. Mol. Biol. 16, 1279-1285. doi:10.1038/nsmb.1700

Tanaka, M., Morishima, I., Akagi, T., Hashikawa, T., and Nukina, N. (2001). Intra- and intermolecular beta-pleated sheet formation in glutamine-repeat inserted myoglobin as a model for polyglutamine diseases. $J$. Biol. Chem. 276, 45470-45475. doi:10.1074/jbc.M107502200

Tao, R. S., Fei, E. K., Ying, Z., Wang, H. F., and Wang, G. H. (2008). Casein kinase 2 interacts with and phosphorylates ataxin-3. Neurosci. Bull. 24, 271-277. doi:10.1007/s12264008-0605-5

Tavanez, J. P., Bengoechea, R., Berciano, M. T., Lafarga, M., CarmoFonseca, M., and Enguita, F. J. (2009). Hsp70 chaperones and type I PRMTs are sequestered at intranuclear inclusions caused by polyalanine expansions in PABPN1. PLoS ONE 4:e6418. doi:10.1371/journal.pone.0006418

Tavanez, J. P., Calado, P., Braga, J., Lafarga, M., and Carmo-Fonseca, M. (2005). In vivo aggregation properties of the nuclear poly(A)-binding protein PABPN1. RNA 11, 752-762. doi:10.1261/rna.7217105

Teplova, M., and Patel, D. J. (2008). Structural insights into RNA recognition by the alternative-splicing 
regulator muscleblind-like MBNL1. Nat. Struct. Mol. Biol. 15, 1343-1351. doi:10.1038/nsmb.1519

Thakur, A. K., Jayaraman, M., Mishra, R., Thakur, M., Chellgren, V. M., Byeon, I. J., et al. (2009). Polyglutamine disruption of the huntingtin exon $1 \mathrm{~N}$ terminus triggers a complex aggregation mechanism. Nat. Struct. Mol. Biol. 16, 380-389. doi:10.1038/nsmb.1570

Tobelmann, M. D., and Murphy, R. M. (2011). Location trumps length: polyglutamine-mediated changes in folding and aggregation of a host protein. Biophys. J. 100, 2773-2782. doi:10.1016/j.bpj.2011.04.028

Todi, S. V., Winborn, B. J., Scaglione, K. M., Blount, J. R., Travis, S. M., and Paulson, H. L. (2009). Ubiquitination directly enhances activity of the deubiquitinating enzyme ataxin-3. EMBO J. 28, 372-382. doi:10.1038/emboj.2008.289

Tzvetkov, N., and Breuer, P. (2007). Josephin domain-containing proteins from a variety of species are active de-ubiquitination enzymes. Biol. Chem. 388, 973-978. doi:10.1515/BC.2007.107

Ventii, K. H., and Wilkinson, K. D. (2008). Protein partners of deubiquitinating enzymes. Biochem. J. 414, 161-175. doi:10.1042/BJ20080798

Vinayagam, A., Stelzl, U., Foulle, R., Plassmann, S., Zenkner, M., Timm, J., et al. (2011). A directed protein interaction network for investigating intracellular signal transduction. Sci. Signal. 4, rs8. doi:10.1126/scisignal.2001699

Vitalis, A., Lyle, N., and Pappu, R. V. (2009). Thermodynamics of beta-sheet formation in polyglutamine. Biophys. J. 97, 303-311. doi:10.1016/j.bpj.2009.05.003

Walters, R. H., and Murphy, R. M. (2009). Examining polyglutamine peptide length: a connection between collapsed conformations and increased aggregation. J. Mol. Biol. 393, 978-992. doi:10.1016/j.jmb.2009.08.034

Walters, R. H., and Murphy, R. M. (2011). Aggregation kinetics of interrupted polyglutamine peptides. J. Mol. Biol. 412, 505-519. doi:10.1016/j.jmb.2011.07.003

Walum, H., Westberg, L., Henningsson, S., Neiderhiser, J. M., Reiss, D., Igl, W., et al. (2008). Genetic variation in the vasopressin receptor la gene (AVPR1A) associates with pair-bonding behavior in humans. Proc. Natl. Acad. Sci. U.S.A. 105, 14153-14156. doi:10.1073/pnas.0803081105

Wang, G., Sawai, N., Kotliarova, S., Kanazawa, I., and Nukina, N. (2000). Ataxin-3, the MJD1 gene product, interacts with the two human homologs of yeast DNA repair protein RAD23, HHR23A and HHR23B. Hum. Mol. Genet. 9, 1795-1803. doi:10.1093/hmg/9.12.1795

Wang, H., Jia, N., Fei, E., Wang, Z., Liu, C., Zhang, T., et al. (2007). $\mathrm{p} 45$, an ATPase subunit of the $19 S$ proteasome, targets the polyglutamine disease protein ataxin-3 to the proteasome. J. Neurochem. 101, 1651-1661. doi:10.1111/j.14714159.2007.04460.x

Weeks, S. D., Grasty, K. C., HernandezCuebas, L., and Loll, P. J. (2011). Crystal structure of a Josephin-ubiquitin complex: evolutionary restraints on ataxin3 deubiquitinating activity. J. Biol. Chem. 286, 4555-4565. doi:10.1074/jbc.M110.177360

Weiss, A., Klein, C., Woodman, B., Sathasivam, K., Bibel, M., Regulier, E., et al. (2008). Sensitive biochemical aggregate detection reveals aggregation onset before symptom development in cellular and murine models of Huntington's disease. J. Neurochem. 104 846-858.

Wetzel, R. (2012). Physical chemistry of polyglutamine: intriguing tales of a monotonous sequence. J. Mol. Biol. 421, 466-490. doi:10.1016/j.jmb.2012.01.030

Whan, V., Hobbs, M., Mcwilliam, S., Lynn, D. J., Lutzow, Y. S., Khatkar, M., et al. (2010). Bovine proteins containing poly-glutamine repeats are often polymorphic and enriched for components of transcriptional regulatory complexes. BMC Genomics 11:654. doi:10.1186/1471-2164-11654

Williams, A. J., and Paulson, H. L (2008). Polyglutamine neurodegeneration: protein misfolding revisited. Trends Neurosci. 31, 521-528. doi:10.1016/j.tins.2008.07.004

Williamson, T. E., Vitalis, A., Crick, S. L., and Pappu, R. V. (2010). Modulation of polyglutamine conformations and dimer formation by the N-terminus of huntingtin. J. Mol. Biol. 396, 1295-1309. doi:10.1016/j.jmb.2009.12.017

Winborn, B. J., Travis, S. M., Todi, S. V., Scaglione, K. M., Xu, P., Williams, A. J., et al. (2008). The deubiquitinating enzyme ataxin-3, a polyglutamine disease protein, edits Lys63 linkages in mixed linkage ubiquitin chains. J. Biol. Chem 283, 26436-26443. doi:10.1074/jbc. M803692200

Winter, R., Liebold, J., and Schwarz, E. (2013). The unresolved puzzle why alanine extensions cause disease. Biol. Chem. doi:10.1515/hsz2013-0112

Yuan, Y., Compton, S. A., Sobczak, K., Stenberg, M. G., Thornton, C. A., Griffith, J. D., et al. (2007). Muscleblind-like 1 interacts with RNA hairpins in splicing target and pathogenic RNAs.
Nucleic Acids Res. 35, 5474-5486. doi:10.1093/nar/gkm601

Zhai, W., Jeong, H., Cui, L., Krainc, D., and Tjian, R. (2005). In vitro analysis of huntingtin-mediated transcriptional repression reveals multiple transcription factor targets. Cell 123, 1241-1253 doi:10.1016/j.cell.2005.10.030

Zhong, X., and Pittman, R. N. (2006). Ataxin-3 binds VCP/p97 and regulates retrotranslocation of ERAD substrates. Hum. Mol. Genet. 15, 2409-2420. doi:10.1093/hmg/ddl164

Zuchner, T., and Brundin, P. (2008). Mutant huntingtin can paradoxically protect neurons from death. Cell Death Differ. 15, 435-442. doi:10.1038/si.cdd.4402261

Conflict of Interest Statement: The authors declare that the research was conducted in the absence of any commercial or financial relationships that could be construed as a potential conflict of interest.

Received: 08 March 2013; accepted: 04 June 2013; published online: 20 June 2013.

Citation: Almeida B, Fernandes $S$, Abreu IA and Macedo-Ribeiro S (2013) Trinucleotide repeats: a structural perspective. Front. Neurol. 4:76. doi: 10.3389/fneur.2013.00076

This article was submitted to Frontiers in Neurodegeneration, a specialty of Frontiers in Neurology.

Copyright () 2013 Almeida, Fernandes, Abreu and Macedo-Ribeiro. This is an open-access article distributed under the terms of the Creative Commons Attribution License, which permits use, distribution and reproduction in other forums, provided the original authors and source are credited and subject to any copyright notices concerning any third-party graphics etc. 